\title{
Research on Formation Identification Based on Drilling Shock and Vibration Parameters and Energy Principle
}

\author{
Yu Ding, ${ }^{1,2,3}$ Zhuoying Tan $\mathbb{D D}^{1,2,3}$ Shuguang Li ${ }^{10},{ }^{4,5}$ Zizhen Miao, $^{5}$ and Huifen $Q u^{1,2,3}$ \\ ${ }^{1}$ School of Civil and Resource Engineering, University of Science and Technology Beijing, Beijing 100083, China \\ ${ }^{2}$ Beijing Key Laboratory of Urban Underground Space Engineering, University of Science and Technology Beijing, \\ Beijing 100083, China \\ ${ }^{3}$ State Key Laboratory of High-Efficient Mining and Safety of Metal Mines, University of Science and Technology Beijing, \\ Beijing 100083, China \\ ${ }^{4}$ Post-Doctoral Research Workstation, China Railway 20th Bureau Group Co., Ltd., Xi'an 710016, China \\ ${ }^{5}$ School of Civil Engineering, Xi'an University of Architecture and Technology, Xi'an 710055, China \\ Correspondence should be addressed to Zhuoying Tan; markzhy_tan@163.com and Shuguang Li; 1ssgg2015@163.com
}

Received 17 December 2020; Revised 29 January 2021; Accepted 9 March 2021; Published 16 April 2021

Academic Editor: Haim Abramovich

Copyright (C) 2021 Yu Ding et al. This is an open access article distributed under the Creative Commons Attribution License, which permits unrestricted use, distribution, and reproduction in any medium, provided the original work is properly cited.

\begin{abstract}
In geotechnical engineering and geological survey, the stratum structure and its corresponding physical and mechanical properties are the most concerned. The stratum structure not only affects the safety of the project but also plays a decisive role in the construction method and construction sequence. In this paper, a new type of stratum geological interface recognition system is adopted, and an R-20 rotary drilling rig is used to conduct on-site drilling experiments for a granite site with no ventilation. The research results show that the system can monitor and record the main parameters (axial pressure, drilling rate, rotation speed, flushing fluid pressure, and torque) of the drilling rig during the drilling process. The comparative analysis of monitoring data and on-site survey results shows that different drilling parameters have different sensitivities to changes in the formation structure. According to the prediction accuracy, the ranking from high to low is drilling rate, axial pressure, torque, rotation speed, and flushing fluid pressure. In drilling engineering, by observing the change law of drilling rig parameters, not only can the position of the special rock mass interlayer be predicted, but also the stratum structure and strength can be identified, and the prediction formula is also given. Based on the established drilling specific energy formula, the energy analysis method is used to predict the formation structure and compressive strength, and the corresponding prediction formula is given. The research results show that, compared with the single drilling parameter prediction method, the rock-soil structure and strength identification method based on energy theory has higher prediction accuracy and can meet engineering needs.
\end{abstract}

\section{Introduction}

In geotechnical engineering, to ensure the rationality, safety, and efficiency of the project, it is usually necessary to carry out a geological survey before the start of the project, to determine the stratum structure and the corresponding physical and mechanical parameters of rock and soil. There are three kinds of common geotechnical engineering survey methods: 1. in situ testing technology: through various penetration tests or drillability tests on the rock and soil mass in the engineering site and then comparing the test results with the empirical values to determine the geotechnical parameters. It mainly includes static penetration test, cone dynamic penetration test, standard penetration test, rock drillability test, and multifunction CPTU test technology. 2. Geophysical exploration technology: this method is an indirect exploration method to detect the geological structure of the stratum and the physical properties of the corresponding rock and soil by detecting the changes of various geophysical fields. It mainly includes the electrical method, magnetic method, gravity method, seismic wave method, and ultrasonic method. 3. Coring laboratory test: this is the most commonly used method in geotechnical engineering at present. The rock and soil samples to be measured are obtained by coring drilling method and then cut by rock 
cutting machine according to the standard size formulated by international rock mechanics society, and finally various forces are carried out in the laboratory according to the requirements of learning experiment. It mainly includes the test of common physical and mechanical parameters such as rock and soil strength, elastic modulus, and Poisson's ratio [1-4]. Compared with the traditional indoor test, in situ testing technology has the advantages of being fast, economic, and continuous, and the test environment is not separated from the original environment, so the test results are more in line with the actual situation of the project, especially for the characteristics of rock and soil before and after the disturbance has obvious advantages. However, due to its test method, it is only applicable in shallow soft rock and soil, but not in deep engineering or hard rock environment $[5,6]$. Geophysical prospecting is an interdisciplinary subject based on geology and physics. Its basic principle is to use the observed geophysical field to infer the changing laws of physical parameters (speed, density, magnetic susceptibility, resistivity, etc.) of the Earth's medium. To analyze and solve geological problems, initially, it was mainly to find geothermal, oil, natural gas, and other prospecting engineering services, with the advantages of wide application range, easy access to parameters, and low cost [7]. However, the geophysical prospecting method has always had the problems of low data inversion accuracy, fewer detection parameters, and diversified calculation results. It usually requires a combination of different methods. The emergence of these problems brings many uncertainties in geotechnical exploration $[8,9]$. In terms of technology maturity, data diversity, and accuracy, the method based on drilling cores and testing in the laboratory is the most reliable one for geotechnical engineering survey and geological drilling engineering [10]. However, the entire operation process is tedious and cumbersome, including drilling and cataloging, sampling, classification and marking, transportation, sample cutting, and instrument measurement, which faces problems such as large workload, time consumption, and high cost. According to statistics, in the process of geological drilling and investigation, the pure drilling time takes less than $30 \%$ of the time in drilling exploration, and the cost of drilling investigation can reach $15 \%-28 \%$ of the total project cost [11]. Compared with in situ testing and geophysical exploration, the coring test method is separated from the original environment of the rock and soil body, and it is difficult to restore the original environment of the rock and soil body in the laboratory test process, so the laboratory will be a certain difference between the result of the test and the value under the undisturbed state. In actual engineering, due to the diversity of geologically developed structures, there may be a large number of special structures such as weak interlayers and broken zones during the survey process, which may lead to problems such as borehole collapse and core failure, resulting in discontinuity of results [12]. In geological drilling and reconnaissance engineering, the borehole depth is usually up to several thousand meters. One-third of the mining depth in China's metal mines has exceeded $1000 \mathrm{~m}$, and the maximum mining depth is close to $5000 \mathrm{~m}$. At the same time, the excavation depth of various deep-buried tunnels, deep coal mines, scientific drilling, and other projects is gradually increasing. According to statistics, the world exceeds $4000 \mathrm{~m}$. There are more than ten deep wells, and the depth of geoscience drilling has exceeded $10,000 \mathrm{~m}$. As the drilling depth increases, the geological conditions will become more complicated. The in situ test method in the aforementioned method is no longer applicable, and the geophysical exploration method suffers more interference factors (high ground temperature, high ground pressure factors); it has a greater impact on many physical parameters, resulting in a single method with low analytical accuracy and multisolution problems which will become more prominent. The coring test method is currently the most used method in deep drilling. However, due to the large depth, the drilling rig needs to be frequently lifted for sampling, which will greatly increase the nondrilling time.

Given the problems of the above methods, some scholars have proposed a method of identifying the formation structure and solving the geological parameters according to the drilling parameters. This method is called measurement while drilling (MWD) and also drilling process monitoring (DPM). This is a type of intelligent drilling monitoring system based on the collection, recording, and analysis of drilling parameters. Its prototype is the instrumented drilling system (IDS). The drilling process monitoring system consists of a series of sensors integrated on the drilling rig, including displacement sensors, pressure sensors, and electromagnetic sensors. Through various sensors connected to the drilling rig and calibrated, a variety of drilling parameters can be monitored and recorded. The main collected drilling parameters include drilling depth, drilling speed, axial pressure, speed, torque, vibration, drilling fluid pressure, and water supply pressure[13]. As early as the 1930s, in the exploration and development of oil and gas wells, instruments have been used to measure and record drilling data to analyze the physical and chemical components of drilling fluids. At present, logging while drilling (LWD), which is widely used in the oil and gas field and ore mining industry, is also a type of measurement while drilling technology. In addition to analyzing the composition of the drilling fluid, it is also used to monitor the working status of the drilling tool, steering and optimizing drilling efficiency. In the following decades, with the development of sensing technology, microelectronics technology, and wireless transmission technology, MWD technology has moved from static monitoring mode to real-time monitoring mode and has made great progress in both software and hardware [14]. Some intelligent detection and analysis systems have been applied to different engineering fields, including Analogue Drilling Parameters (ADP) [15], Enpasol system [16], Papero system [17], and Automated Drill Monitor (ADM) system [18].

Since the 1970s, scholars in different countries have begun to pay attention to the parameter recording instrument while drilling and hope to use this technology to solve some difficulties in the division of strata in geotechnical engineering drilling and develop the division of strata structure based on drilling parameters, research on weak interlayer identification, engineering rock mass quality evaluation, blasting parameter optimization, etc. Many scholars have made beneficial attempts on the identification of stratum structure and the parameters of rock and soil 
based on drilling parameters. Tsoutrelis [19] once proposed a drilling method to determine the compressive strength of the rock in situ or on small-sized rocks by using a diamond drilling rig and gave a prediction formula based on the drilling rig's propulsion force and drilling rate. Compared with the coring test, the advantages of this method are the following: (a) there is no need to cut the rock sample, and the parameter acquisition is convenient and quick; (b) it is not affected by the internal cracks or discontinuities of the rock; (c) it is performed on the whole rock. The compressive strength obtained by the test is more in line with the actual situation. Howarth et al. [20] studied the relationship between the drilling parameters obtained during tunnel drilling and the physical and mechanical properties of the tunnel surrounding rock and found that there is a relationship between the speed and other parameters obtained during tunnel drilling and the rock mass strength. Certain response used a rotary percussion drill equipped with an ADM automated drilling monitoring system to conduct drilling experiments and mainly monitored the effective thrust and drilling speed during the drilling process. The results show that the changes in drilling parameters are related to the lithology of the drilled rock mass and physical and mechanical parameters (compressive strength, tensile strength, and elastic modulus), from the perspective of changes in drilling parameters and drilling energy consumption analyzed. Schunnesson [22] established a rock quality (RQD) prediction method based on drilling parameters by changing the drilling rate and torque during the granite tunnel excavation. Gui et al. [23] used instruments in geotechnical engineering surveys to classify formation quality based on drilling parameters. This method can be used for engineering site surveys, identification of weak coal seams in hard rocks, rock mass engineering grading, and foundation reinforcement. However, in this study, it was found that the drilling rig power changes will cause random changes in the drilling rate and other parameters. At the same time, the drilling rig vibration will cause a lot of invalid monitoring data. Therefore, it is necessary to keep the drilling rig output hydraulic power constant during the drilling process. Variable and constant power reduce the impact of random vibration of the drilling rig. Yue et al.'s [24-28] team at the University of Hong Kong independently developed a drilling process monitoring system (DPM), which can automatically and continuously monitor and record various parameters of the drilling rig. There have been beneficial attempts in geotechnical engineering such as layer identification, engineering survey, and engineering quality rating, and fruitful results have been achieved. S. S. Peng [29] et al. developed a method to predict roof geological conditions based on drilling parameters during roof bolt drilling. In this study, a series of indoor and on-site underground tests were carried out. The research results show that the thrust pressure is a good indicator for identifying void and broken areas and evaluating the strength of roof rocks. Zhou et al. [30] proposed an automatic lithology identification method based on spectral feature analysis and pointed out that automatic lithology identification is a key link in the establishment of intelligent mines. When identifying lithology by spectrum, the main challenge is that there is no clear oneto-one correspondence between the two. The clustering fusion method based on the Gaussian regression process can improve the recognition rate of lithology. KadkhodaieIlkhchi et al. [31] used three methods: boosting algorithm, neural network algorithm, and fuzzy algorithm to analyze shale and iron ore according to the drilling parameters such as bit pressure, torque, and drilling speed measured by the measurement while drilling system. The lithology and strength of the rock are identified, and the results show that the drilling parameters can reflect the lithology and strength information of the drilled formation and the boosting algorithm is better than the other two algorithms. Zang [32] used the Q2J200B percussion drill to carry out drilling tests on the tunnel excavation site. Through the comparative analysis of a large number of field measured data and laboratory tests, the drilling speed and rock compressive strength, surrounding rock category and rock BQ were established. The statistical relationship. Tian et al. [33] and other subsea tunnel cross section excavation processes found that the drilling rig parameters monitored during the drilling process were analyzed by energy theory, and it was found that the response degree of digital drilling rig parameters and surrounding rock lithology in tuff was high and the change of drilling specific energy can be used to divide corresponding rock mass sections and judge surrounding rock grade. Patel [34] conducted drilling experiments on three sites with different lithologies in Mauritius by monitoring the drilling rate, torque, and axial pressure during the drilling process of the down-the-hole hammer. The method of advanced parameter analysis can accurately identify the location of underground holes. Liu et al. [35] found that the roof anchoring drilling device in coal roadways has different dynamic responses to different rock types, which can indirectly reflect the thickness and strength of the rock layer. Leung and Scheding [36] et al. used a method based on the power change of the drilling rig to predict the change law of coal and rock formations, and this method can significantly improve the efficiency of open-pit mining. Su et al. [37] et al. found through laboratory experiments that the drilling rate index (DRI) has a strong correlation with the uniaxial compressive strength of rock, but it has a weak correlation with the elastic modulus. Asadi et al. [38] and Fang et al. [39] proposed a neural network-based intelligent analysis of drilling test data and formation identification methods. They conducted an in-depth analysis of advanced drilling test data. The results showed that a single drilling parameter is used for formation identification. The error rate of the neural network drilling test under the multiparameter combination is significantly lower for the randomly sampled formation recognition error rate. The drilling speed, torque, number of revolutions, and propulsion are relatively more sensitive to formation recognition. Gao et al. [40] conducted indoor drilling tests on concrete and sandstone samples, and the results showed that the torque, axial pressure, drilling speed, and other parameters in the drilling process are consistent with the change law of the uniaxial compressive strength of the rock. A quantitative model (CDP-UCS model) between drilling parameters and rock compressive strength was 
established according to the fracture characteristics of the rock during the drilling process.

In addition to engineering field test methods and statistical analysis methods based on drilling process parameters, the analysis process based on energy principles has also been used by some scholars in formation identification and rock mechanics parameter acquisition. As early as the 1960s, Teale [41] proposed the concept of specific energy of chipping and established the mechanical expression of rock strength based on the drilling parameters monitored in the indoor drilling test. The principle of chipping specific energy is to classify the rock drillability according to the energy required for the destruction of a unit volume of rock mass and then select a reasonable drill bit and determine the production quota. This method is then used in the fields of geological survey, drilling petroleum, and other fields. Karasawa et al. [42] defined the effective axial force energy per revolution and the effective rotational energy per revolution during the drilling process and studied the relationship between these two energy parameters and rock strength. The test results show that the method can effectively estimate rock strength and define rock drillability. Tan et al. [43-46] used a drilling rig installed with a drilling monitoring system to conduct a drilling survey test on a complex weathered granite site, monitoring and recording drilling parameters such as effective axial pressure, rotation speed, and drilling rate, and, from the energy point of view, the drilling parameters and formation change rules and rock strength identification are analyzed. By comparing with the results of manual hole recording on-site, it is found that the boundary division of the strata structure based on drilling parameters and the prediction of rock and soil mechanical parameters have high credibility, which can meet engineering needs. Based on the energy analysis method, Wang et al. [11] proposed a method for testing the uniaxial compressive strength of rock based on digital drilling, deduced the relationship between the unit cutting energy of rock and the parameters while drilling, and established the relationship between the parameters while drilling and the rock. The quantitative relationship model of uniaxial compressive strength (DP-UCS model) was tested by a functional rock drilling test system based on self-development, and the test results showed that the error of the model was less than 10\%. Tian et al. [33] and Li et al. [47] established an energy equation based on the drilling process and conducted drilling tests in the tuff formation. The results showed that the drilling rig parameters and drilling energy surrounding rock lithological response were high and passed the analysis of the energy curve which found that the drilling energy can be used to classify rock mass sections, determine the grade of surrounding rock, and predict faults. Chen et al. [48] et al. monitored the pressure and flow rate of the hydraulic system of the drilling rig and analyzed and calculated the change law of the output power of the drilling rig based on this. They proposed a method to identify the roof rock formation during the tunneling process and derived the strength of the roof rock formation. The formula for calculating the parameters while drilling is used to locate the position of the rock formation interface and the weak interbed. At present, energy analysis-based methods are mostly determined by the method of impact crushing in the laboratory, and most of them only consider a single drilling type. At the same time, because the laboratory environment is separated from the natural formation environment, it lacks ground stress, pore water pressure, temperature, acid corrosion [49, 50], and other influencing factors; the obtained specific energy is difficult to reflect the real situation of the project site. At the same time, in actual drilling, a large amount of energy will be dissipated in the form of sound, heat, and friction. This part of energy is usually difficult to measure, which brings some bottlenecks to the development of the specific energy method.

It can be seen from the above analysis that there have been many studies on the division of stratum structure, the identification of special structures, and the prediction of mechanical parameters of rock and soil based on drilling parameters, and related scholars have also developed monitoring systems suitable for different geological environments. However, most of these systems currently collect data according to the drilling depth, but, since the actual drilling process involves a large amount of auxiliary work such as drilling preparations and drill tool adjustments, these nondrilling processes will also be recorded in the data collection, resulting in a large amount of invalid data; how to identify the pure drilling process still needs a lot of work [27]. At present, relevant researches mostly focus on the use of a single parameter for analysis. However, due to a large amount of calculation, the complex underground environment, and the numerous interference factors, the drilling parameters of the drilling rig are greatly affected by the operating habits of the operator and the single parameter is directly used for geotechnical analysis. The prediction of body parameters is quite random. Reasonable use of effective drilling parameters, to quickly and accurately predict the strength of stratum and rock-soil mass and to provide a reasonable basis for geotechnical engineering survey, mine safety, tunnel surrounding rock support [51-53], etc., is still important for the future development of geotechnical engineering as one of the directions. In this paper, based on the geological identification while drilling system (GWID) independently developed by the research group, the five parameters of axial pressure, drilling rate, rotation speed, flushing fluid pressure, and torque will be monitored in real time during the drilling process and recording. By comparing the monitoring data with the field test results, the corresponding relationship between the drilling parameters and the weathering degree of granite and the compressive strength of the rock mass is determined. Finally, through the energy analysis angle of the multiparameter fusion algorithm, the lithology classification and the compressive strength of the rock and soil are predicted, and the corresponding regression equation is given to provide a reference for future related research. 


\section{Introduction of Geological Identification While Drilling System (GWID)}

2.1. Composition and Working Principle of the System. In the construction of high-energy geological environment tunnels, the surrounding rock often releases much energy after being disturbed. MWD technology is an automated technology that installs monitoring instruments on a drilling rig to collect data during the drilling process. Its prototype is an instrument drilling system. At first, these systems were mainly used to measure basic physical quantities such as temperature and pressure in boreholes. With the development of intelligent geotechnical engineering, scientific researchers and commercial companies in different countries and regions have developed many intelligent identification systems based on drilling process monitoring [15-18]. These MWD systems are dedicated to the measurement of drilling rig parameters such as drilling trajectory, drilling depth, axial pressure, torque, and drilling speed and perform corresponding intelligent geotechnical surveys accordingly. However, in deep geotechnical engineering, drilling is limited by three tenors: one disturbance geological mechanics environment (high ground temperature, high ground stress, high permeability pressure, and mining disturbance), sensor and hole wall contact stability, and the accuracy of the obtained parameters and signal transmission problems. Further research is needed.

To accurately describe the geological environment through drilling rig parameters, the drilling process needs to be as close to the ideal state as possible. If there is no sticking or blowout accident, the drill cuttings should be discharged from the bottom of the hole in time, the drill bit should not be excessively worn, and the power of the drill should not change too much [23]. In practical applications, these situations cannot be completely avoided, and the operator will adjust the drilling rig in real time according to the on-site situation. There are many drilling subprocesses or auxiliary actions, which makes a lot of invalid data in the drilling parameters. Based on the above situation, this section will introduce a geological identification while drilling (GIWD) based on the traditional drilling process monitoring system. Different from the traditional monitoring system, this system can collect and record parameters according to time series. It can filter auxiliary actions such as drilling rig adjustments during drilling. Combining process identification commands, it can perform reasonable screening and identification of pure drilling processes. The GIWD system is mainly composed of three parts: (1) sensing system (SS), (2) data logging (DL), and (3) data analysis (DA). The design layout is shown in Figure 1.

The sensing system (SS) is mainly used to monitor the physical parameters of the borehole through sensors installed on the console or drill stand. These sensors include displacement sensors, rotation sensors, pressure sensors, flow sensors, temperature sensors, vibration sensors, stress sensors, and other components used to record the drilling depth, displacement, drilling speed, rotational speed, various working pressures, flushing fluid pressure and flow, fuel consumption, temperature, vibration acceleration, and drill pipe stress waves during drilling. The data acquisition system (DL) is installed on the ground workbench for data conversion and transmission. This part includes the conversion box, digital strain gauge, and data integration box. The main function is to convert the data collected by the sensor system by the conversion box. Then, a digital strain gauge is converted into a digital signal and put into the data integration box and finally uploaded to the terminal equipment of the data analysis system. The data analysis unit (DA) is generally installed in the test site, construction office, etc. The terminal is generally composed of a computer, printer, modem, rangefinder, and external display instrument and performs data analysis and output through wired or wireless transmission.

2.2. Extraction Principle of Drilling Rig Parameters. The working parameters in the drilling process are mainly pressure, speed, displacement, etc., all of which are vectors. Work pressure is mainly divided into push pressure and feedback pressure. For the vertical oil cylinder, the thrust pressure is to generate axial pressure on the drilling tool to make the drilling tool move downward; for the horizontal oil cylinder, its function is to generate a horizontal thrust on the drilling tool, so that the drilling rig moves along the horizontal guide rail on its base. The adjustment force is applied to the drilling tool during forwarding movement or during drilling to adjust the drilling direction. The effect of the feedback force is opposite to the above. The displacement of the drilling tool will be realized through pressure adjustment, and its vector is determined by the positive and negative identification of the sensor data. There are two directions of rotation: clockwise and counterclockwise. The rotation speed sensor is based on the pulse signal generated by the electromagnetic principle to record data. The rotation vector can be recognized through the combination of two sensors and the time difference. The drilling displacement is reflected by the piston movement, which is divided into upward and downward displacement. The laser sensor is used to calibrate the change in the measured displacement of the piston rod when it moves. An increase in displacement indicates that the piston rod moves downward, and a decrease in displacement indicates that the piston rod moves upward.

2.3. Drilling Process Division and Coding Principles. In geotechnical engineering and geological prospecting, drilling rigs with PDC or cone bits are often used for rotary drilling and drilling. To complete a drilling task, many actions of the drilling rig are required to be achieved. The main processes include the following: (1) loading the drill rod, (2) moving the drill rig forward horizontally, (3) connecting the drill rod, (4) drilling, (5) raising the extension rod, (6) installing the extension rod, (7) making horizontal backward movement of the drilling rig, (8) unloading the drill rod, (9) having original position test, such as standard penetration 


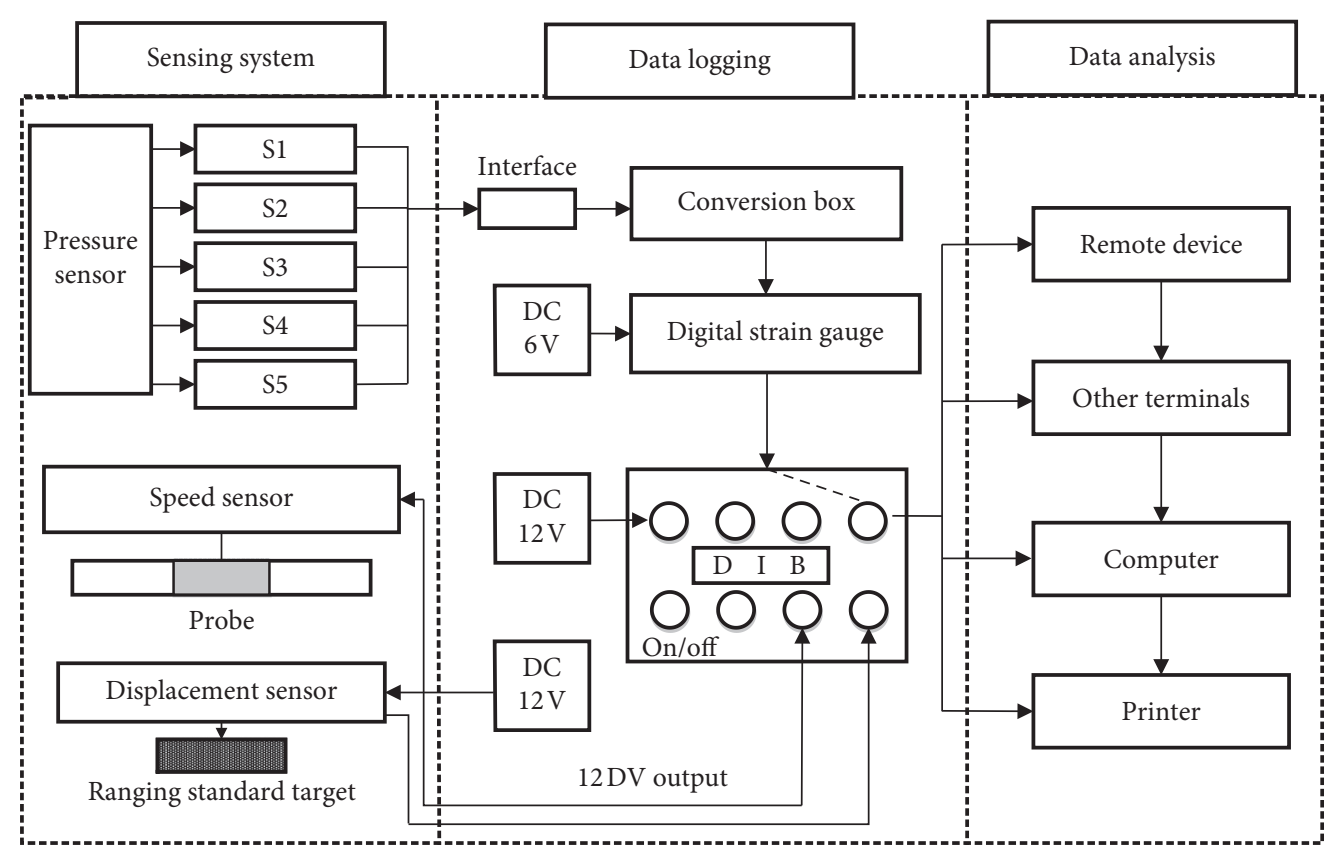

Figure 1: Structural design of geological identification while drilling system.

test, and (10) idling. These main processes also include a series of secondary actions. To better identify these primary and secondary actions, it is necessary to determine the status of each drilling action. Taking the first four movements involving the movement of the drilling rig as an example, the description of the process state switches is shown in Tables 1 to 4 . Number 1 in the table represents the "on" state, and 0 represents the "off" state; that is, on $=1$ /off $=0$.

After the drilling process is divided, if you want to realize the automatic identification of the target process, you need to analyze the main process and the secondary process in the drilling process. From the above table, it can be seen that any drilling action is controlled by a series of parameter states. According to the different state parameters, the drilling action can be monitored, so that the computer system can automatically identify. These state parameters will correspond to a multidigit character string. Through the computer binary processing mode, an 8-digit character string can be formed. The missing state of the process is filled with 0 . Take the pure drilling process identification code 10100101 in Table 4 as an example; the first digit " 1 " indicates that the pressure is "on," that is, the state of applying axial pressure at this time; the second digit " 0 " indicates that the feedback pressure is "off" state; that is, there is no intervention of regulating pressure at this time; the third digit " 1 " indicates that the flushing fluid pressure is "on;" that is, the flushing fluid is sprayed into the working state at this time; the fourth digit " 0 " indicates the back movement is in the "on" state, indicating that the drill rod is in the backward movement state at this time; the meaning of the subsequent parameters can be deduced by analogy. It is worth noting that the same process may correspond to different identification codes. For example, it is also a pure drilling process. When the drilling depth is large and the drilling speed exceeds a reasonable value, the system will apply feedback pressure (pressure adjustment). The code will be 01100101 (the other state is 10100101). Taking the pure drilling process as an example, the system identification code is shown in Table 5 .

Besides, for each parameter, a threshold value under working conditions needs to be set. The drilling rig can be set to the working state corresponding to a certain parameter that needs to be calibrated. When the monitored parameter reaches a stable state, record this value and then stop the drilling rig. At this time, the parameter will gradually be converted to a nonworking state and eventually returns the initial value. The stable value of the working state recorded in this process is the threshold value of this parameter. The threshold value of different drilling rig systems will vary slightly. Taking the R-20 drilling rig as an example, Table 6 gives the recommended threshold values of each state parameter, 1 bar $=0.102 \mathrm{MPa}$.

\subsection{GIWD System Process Identification Logic Diagram.} The process identification of the GIWD system includes the following steps: (1) set the sensor to collect data; (2) according to the calibration equation, convert the collected raw data into readable physical parameters; (3) compare the physical parameters with the threshold value and the status of the subprocess, making a judgment and generating the state number " 0 " or " 1 "; (4) generate the subprocess information chain from the state number, that is, the identification code of the su-process; (5) read the subprocess verification code to verify the subprocess; (6) generate process code; (7) read the process verification code to check the main process; (8) generate process curve. Figure 2 is a logical flowchart of the entire recognition process. 
TABLE 1: The status of each working parameter in the process of loading the drill pipe.

\begin{tabular}{|c|c|c|c|c|c|c|c|c|}
\hline Subprocess & $\begin{array}{c}\text { Feed } \\
\text { pressure }\end{array}$ & $\begin{array}{c}\text { Feedback } \\
\text { pressure }\end{array}$ & $\begin{array}{l}\text { Flushing } \\
\text { pressure }\end{array}$ & $\begin{array}{c}\text { Back } \\
\text { movement }\end{array}$ & $\begin{array}{c}\text { Move } \\
\text { forward }\end{array}$ & $\begin{array}{c}\text { Drill } \\
\text { rotation }\end{array}$ & $\begin{array}{l}\text { Electric hoist } \\
\text { rotation }\end{array}$ & $\begin{array}{c}\text { Bit } \\
\text { displacement }\end{array}$ \\
\hline Lower sling & 0 & 0 & 0 & 0 & 0 & $\begin{array}{l}0 \\
1\end{array}$ & 0 & 0 \\
\hline $\begin{array}{l}\text { Connect the drill } \\
\text { pipe }\end{array}$ & 0 & 0 & 0 & 0 & 0 & $\begin{array}{l}0 \\
1\end{array}$ & 0 & 0 \\
\hline Lift the drill pipe & 0 & 0 & 0 & 0 & 0 & $\begin{array}{l}0 \\
1\end{array}$ & $\begin{array}{l}0 \\
1\end{array}$ & 0 \\
\hline $\begin{array}{l}\text { Lower the drill } \\
\text { pipe }\end{array}$ & 0 & 0 & 0 & 0 & 0 & $\begin{array}{l}0 \\
1\end{array}$ & 0 & 0 \\
\hline Connect cable & 0 & 0 & 0 & 0 & 0 & 0 & 0 & 0 \\
\hline $\begin{array}{l}\text { Tighten the } \\
\text { chuck }\end{array}$ & 0 & 0 & 0 & 0 & 0 & $\begin{array}{l}0 \\
1\end{array}$ & $\begin{array}{l}0 \\
1\end{array}$ & 0 \\
\hline $\begin{array}{l}\text { Stop the drill } \\
\text { pipe }\end{array}$ & 0 & 0 & 0 & 0 & 0 & 0 & 0 & 0 \\
\hline
\end{tabular}

TABLE 2: The status of each working parameter during the forward movement of the rig.

\begin{tabular}{|c|c|c|c|c|c|c|c|}
\hline $\begin{array}{l}\text { Feed } \\
\text { pressure }\end{array}$ & $\begin{array}{c}\text { Feedback } \\
\text { pressure }\end{array}$ & $\begin{array}{l}\text { Flushing } \\
\text { pressure }\end{array}$ & $\begin{array}{c}\text { Back } \\
\text { movement }\end{array}$ & $\begin{array}{c}\text { Move } \\
\text { forward }\end{array}$ & $\begin{array}{c}\text { Drill } \\
\text { rotation }\end{array}$ & $\begin{array}{c}\text { Electric hoist } \\
\text { rotation }\end{array}$ & $\begin{array}{c}\text { Bit } \\
\text { displacement }\end{array}$ \\
\hline \multirow[t]{2}{*}{0} & \multirow[t]{2}{*}{0} & 0 & \multirow[t]{2}{*}{1} & 0 & \multirow[t]{2}{*}{0} & \multirow[t]{2}{*}{0} & \multirow[t]{2}{*}{0} \\
\hline & & 1 & & 0 & & & \\
\hline
\end{tabular}

TABLE 3: The status of each working parameter of the drill pipe connection process.

\begin{tabular}{|c|c|c|c|c|c|c|c|c|}
\hline Subprocess & $\begin{array}{c}\text { Feed } \\
\text { pressure }\end{array}$ & $\begin{array}{c}\text { Feedback } \\
\text { pressure }\end{array}$ & $\begin{array}{l}\text { Flushing } \\
\text { pressure }\end{array}$ & $\begin{array}{c}\text { Back } \\
\text { movement }\end{array}$ & $\begin{array}{c}\text { Move } \\
\text { forward }\end{array}$ & $\begin{array}{c}\text { Drill } \\
\text { rotation }\end{array}$ & $\begin{array}{c}\text { Electric hoist } \\
\text { rotation }\end{array}$ & $\begin{array}{c}\text { Bit } \\
\text { displacement }\end{array}$ \\
\hline $\begin{array}{l}\text { Lower the drill } \\
\text { pipe }\end{array}$ & 1 & $\begin{array}{l}0 \\
1 \\
\end{array}$ & 0 & $\begin{array}{l}0 \\
1 \\
\end{array}$ & $\begin{array}{l}0 \\
1 \\
\end{array}$ & 0 & 0 & 1 \\
\hline Positioning & $\begin{array}{l}1 \\
0 \\
\end{array}$ & $\begin{array}{l}0 \\
1 \\
\end{array}$ & 0 & $\begin{array}{l}1 \\
0 \\
\end{array}$ & $\begin{array}{l}1 \\
0 \\
\end{array}$ & 0 & 0 & 0 \\
\hline $\begin{array}{l}\text { Connect the drill } \\
\text { bit }\end{array}$ & 0 & 0 & 0 & 0 & 0 & $\begin{array}{l}1 \\
0 \\
\end{array}$ & $\begin{array}{l}1 \\
0 \\
\end{array}$ & 1 \\
\hline
\end{tabular}

TABLE 4: The status of each working parameter of the drill pipe drilling process.

\begin{tabular}{|c|c|c|c|c|c|c|c|c|c|}
\hline \multicolumn{2}{|c|}{ Subprocess } & $\begin{array}{c}\text { Feed } \\
\text { pressure }\end{array}$ & $\begin{array}{l}\text { Feedback } \\
\text { pressure }\end{array}$ & $\begin{array}{l}\text { Flushing } \\
\text { pressure }\end{array}$ & $\begin{array}{c}\text { Back } \\
\text { movement }\end{array}$ & $\begin{array}{c}\text { Move } \\
\text { forward }\end{array}$ & $\begin{array}{c}\text { Drill } \\
\text { rotation }\end{array}$ & $\begin{array}{c}\text { Electric hoist } \\
\text { rotation }\end{array}$ & $\begin{array}{c}\text { Bit } \\
\text { displacement }\end{array}$ \\
\hline $\begin{array}{l}\text { Pure } \\
\text { drilling }\end{array}$ & $\begin{array}{l}\text { Apply shaft } \\
\text { thrust }\end{array}$ & 1 & $\begin{array}{l}0 \\
1 \\
\end{array}$ & 1 & $\begin{array}{l}0 \\
1 \\
\end{array}$ & $\begin{array}{l}0 \\
1 \\
\end{array}$ & $\begin{array}{l}1 \\
0 \\
\end{array}$ & $\begin{array}{l}1 \\
0 \\
\end{array}$ & 1 \\
\hline & Apply torque & $\begin{array}{l}1 \\
0\end{array}$ & $\begin{array}{l}0 \\
1 \\
\end{array}$ & 1 & $\begin{array}{l}0 \\
1 \\
\end{array}$ & $\begin{array}{l}0 \\
1 \\
\end{array}$ & $\begin{array}{l}1 \\
0 \\
\end{array}$ & $\begin{array}{l}1 \\
0 \\
\end{array}$ & 1 \\
\hline Rinse & $\begin{array}{l}1 \\
0 \\
\end{array}$ & $\begin{array}{l}0 \\
1 \\
\end{array}$ & 1 & 0 & 0 & $\begin{array}{l}1 \\
0\end{array}$ & 0 & $\begin{array}{l}1 \\
0 \\
\end{array}$ & \\
\hline $\begin{array}{l}\text { Piston } \\
\text { stroke }\end{array}$ & $\begin{array}{l}\text { Release the } \\
\text { chuck } \\
\text { Lift the } \\
\text { rotating head } \\
\text { Tighten the }\end{array}$ & 0 & 1 & 1 & 0 & 0 & 0 & 0 & 1 \\
\hline
\end{tabular}

\section{Test Engineering Background and Typical Rig Parameters}

According to the preliminary survey, the drilling test site is mainly composed of multilayered ordinary weathered granite strata and complex weathered granite strata. The corresponding rock masses are mainly fine to mediumgrained granites from the Jurassic to Cretaceous. The main structure of the stratum is the overlying fill, slightly weathered to fully weathered granite layer, and loose body. The thickness of each layer is different. The weathering grade of granite is IV-II. A total of more than 30 exploration 
TABLE 5: Identification code of the drilling process.

\begin{tabular}{|c|c|c|c|}
\hline Main process & & Subprocess & Identification code \\
\hline \multirow{6}{*}{ Drilling } & \multirow{3}{*}{ Pure drilling } & Apply shaft thrust & $1 \mathrm{x} 1 \mathrm{x} \times x 01$ \\
\hline & & Apply torque & $\mathrm{xx} 1 \mathrm{x}$ xx01 \\
\hline & & Rinse & $\mathrm{xx} 100 \mathrm{x} 0 \mathrm{x}$ \\
\hline & \multirow{3}{*}{ Piston stroke } & Release the chuck & 00100000 \\
\hline & & Lift the rotating head & 01100001 \\
\hline & & Tighten the chuck & 01100000 \\
\hline
\end{tabular}

TABLE 6: Threshold value of each state of drilling subprocess.

\begin{tabular}{|c|c|c|c|c|}
\hline Process parameters & Status symbol & Number of states & Threshold & Max \\
\hline Feed pressure & On & 1 & $\geq 0.40$ bar & 100 bar \\
\hline Feedback pressure & On & 1 & $\geq 1.25$ bar & 150 bar \\
\hline Flushing pressure & On & 1 & $\geq 0.20$ bar & 20 bar \\
\hline Move forward & On & 1 & $\geq 10$ bar & 50 bar \\
\hline Back movement & On & 1 & $\geq 10$ bar & 50 bar \\
\hline Drill rotation & On & 1 & $\geq 10 \mathrm{r} / \mathrm{m}$ & $500 \mathrm{r} / \mathrm{m}$ \\
\hline Electric hoist rotation & On & 1 & $\geq 5 \mathrm{r} / \mathrm{m}$ & $300 \mathrm{r} / \mathrm{m}$ \\
\hline Bit displacement & On & 1 & $\geq 248 \mathrm{~mm}$ & $886 \mathrm{~mm}$ \\
\hline
\end{tabular}

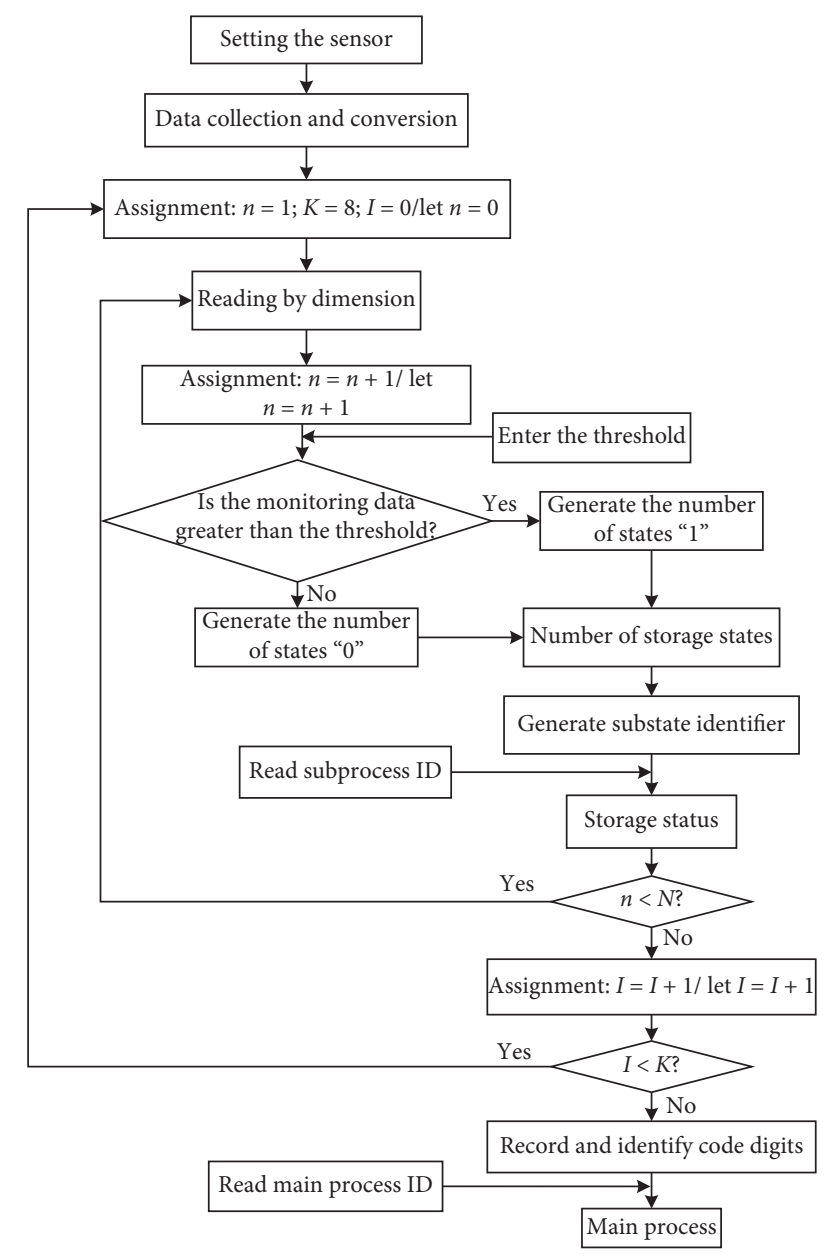

Figure 2: Logic flowchart of procedure identification for GIWD.

boreholes were arranged on-site. Some boreholes were drilled using the installed GWID drilling process monitoring system. Through real-time monitoring of drilling process parameters, the pure drilling subprocess was obtained. At the same time, combined with field tests such as on-site hole recording and in-situ testing, the rock formations are measured on-site to obtain rock mass classification and uniaxial compressive strength indicators, and the corresponding numerical correspondences are established through the combined analysis with the drilling process parameters.

The drilling rig adopts $\mathrm{R}-20$ hydraulic rotary drilling rig. The drilling rig adopts diamond drill bits. The inner diameter of the drill bit is $84 \mathrm{~mm}$, the outer diameter is $115 \mathrm{~mm}$, the diameter of the drill rod is $100 \mathrm{~mm}$, and the quality of the drill rod is about $60 \mathrm{~kg} / \mathrm{m}$. The drilling fluid uses clean natural water. The main monitoring parameters are axial pressure $F_{e}$, drill bit speed $r_{v}$, drill bit displacement $h$, flushing fluid pressure $F_{w}$, drilling rate $v_{p}$, and torque $M_{d}$. Figures 3 to 8 are schematic diagrams of the main process parameters of the typical borehole 2 changing with the drilling depth. At the same time, according to the field survey results, the strata of different depths were graded according to the strength index (see Table 7 for the specific classification basis). The relationship between the classification results and the depth is shown on the right side of the figure.

According to on-site geological data, the borehole is located approximately $4.1 \mathrm{~m}$ below the average elevation of the site. According to the on-site stratum grading results, the rock-soil strength of the corresponding stratum of the borehole ranges from grade VI to grades II/I (grade VI is filling soil and grade II/I is rock vein). As the drilling depth increases, the formation classification results show a certain regularity; that is, the strength gradually increases with the increase of depth. Based on the on-site monitoring data map corresponding to the drilling hole, it is found that the formation of different rock grades has a significant impact on the drilling rig axial pressure, drilling rate, and other 


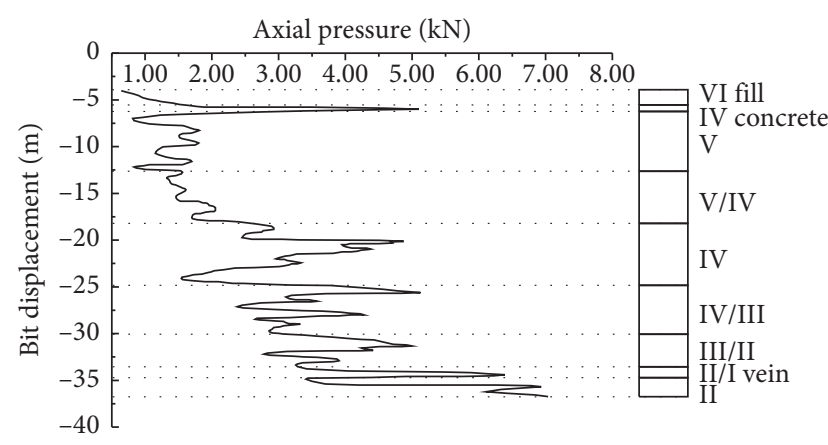

Figure 3: Axial pressure change graph.

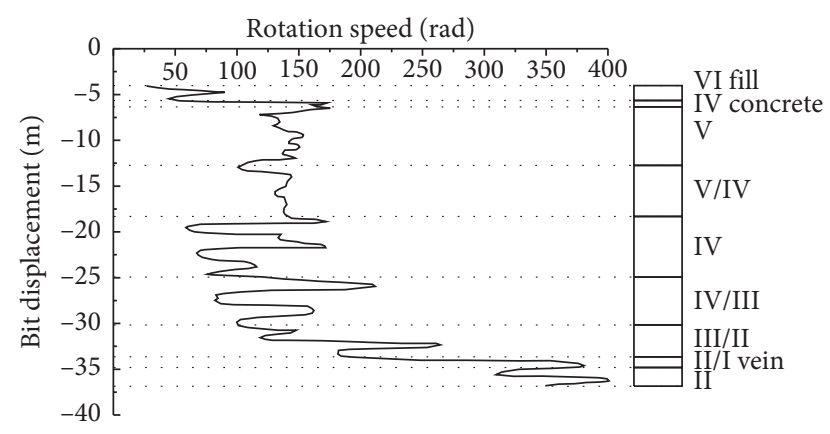

FIGURE 4: Rotation speed change graph.

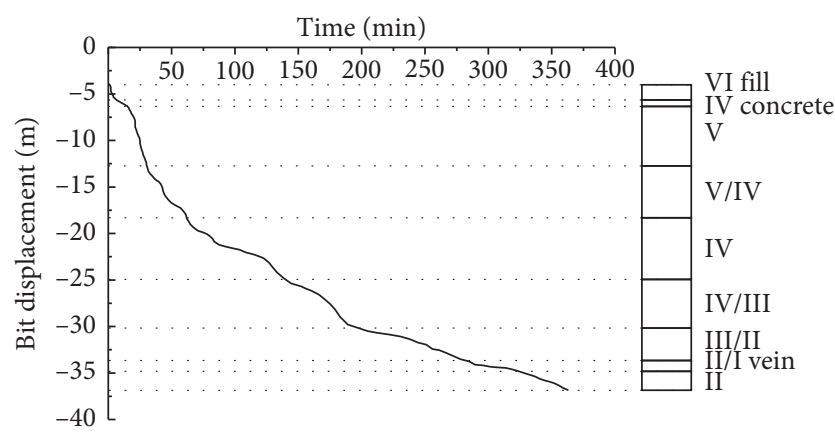

FIGURE 5: Bit displacement change graph.

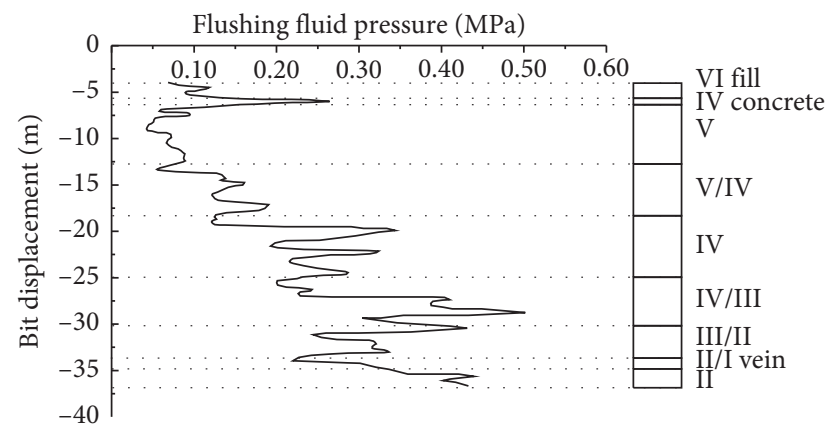

FIgURE 6: Flushing fluid pressure change graph.

parameters. It is feasible to use the variation law of drilling process parameters to distinguish the formation. From the diagram of bit displacement and drilling time (Figure 5) and the diagram of drilling rate (Figure 7), it can be seen that the

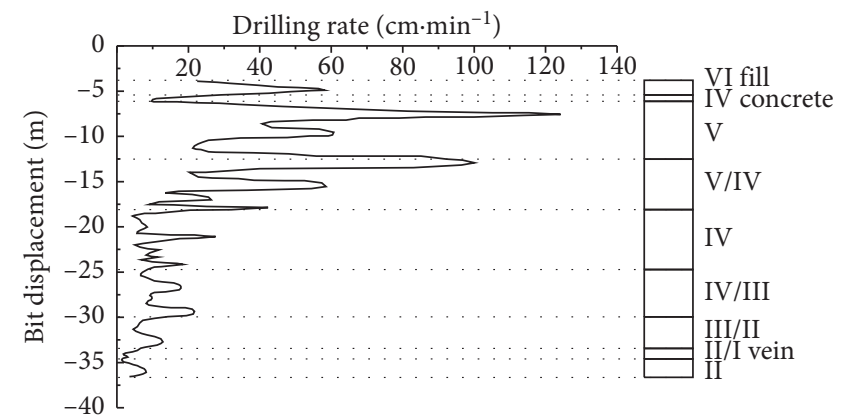

Figure 7: Grilling rate change graph.

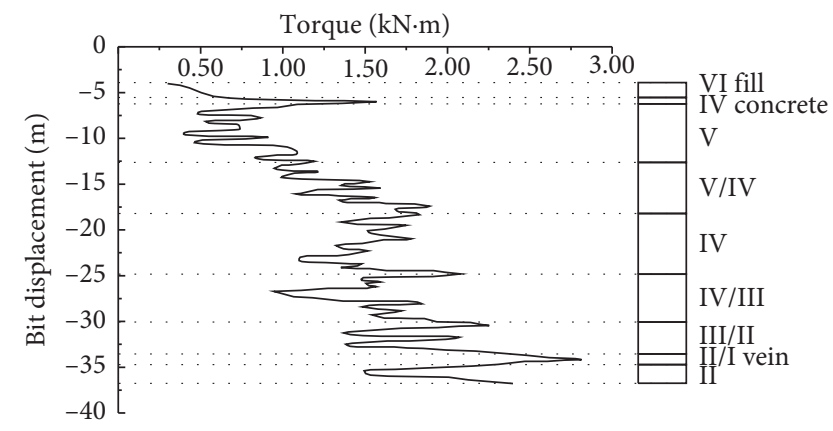

Figure 8: Torque change graph.

drilling speed of the drill bit at different depths and different times has obvious differences. Generally speaking, it can be divided into three sections: the drilling rate is faster in the depth range above $-13.2 \mathrm{~m}$, the drilling rate is moderate in the depth range from $-13.2 \mathrm{~m}$ to $-30.2 \mathrm{~m}$, and the drilling rate is slower in the depth range below $-30.2 \mathrm{~m}$. From the field survey data, it can be seen that the rock mass strength of the formation with a faster drilling rate is lower and the rock mass strength of the formation with a slower drilling rate is greater. This shows that the drilling parameters are closely related to the formation structure and strength. From the variation law of axial pressure with drilling depth (Figure 3), it can be seen that the axial pressure is smaller in the area where the drilling rate is faster and the axial pressure is larger in the area where the drilling rate is slow. At the same time, the rotation speed, flushing fluid pressure, and torque also showed similar changes with the increase in depth, indicating that there is a strong correlation between different parameters. Among them, the rotation speed, axial pressure, and torque all increase with the decrease of the drilling rate, while the flushing fluid pressure increases with the increase of the drilling rate.

It is worth noting that there is a concrete interlayer at $-5.5 \mathrm{~m}$ to $-6.2 \mathrm{~m}$ in the borehole, which is classified as grade IV according to the strength grade. The rock veins from $-33.6 \mathrm{~m}$ to $-34.7 \mathrm{~m}$ are classified as II/I according to the strength grade. The two strata did not satisfy the law that the strength increases with the increase of depth; that is, the phenomenon of stratigraphic interlacing occurred. Within the depth of the concrete interlayer, there are obvious data mutations in the axial pressure, flushing fluid 
TABLE 7: Classification and compressive strength of weathered granite.

\begin{tabular}{lcc}
\hline Rock classification & Degree of weathering & Compressive strength (MPa) \\
\hline VI (fill) & Fill soil & 0.06 \\
V & Fully weathered & 0.7 \\
V/VI & Fully weathered-highly weathered & 12.92 \\
IV (concrete) & Reference height weathering & 28.44 \\
IV & Highly weathered & 35.85 \\
IV/III & Highly weathered-medium weathered & 52.76 \\
III & Moderate weathering & 67.62 \\
III/II & Medium weathering-light weathering & 86.81 \\
II & Light weathering & 100.36 \\
II/I (vein) & Slightly weathered-unweathered & 115.78 \\
\hline
\end{tabular}

pressure, perforation rate, and torque. Within the depth of the rock vein, the axial pressure, rotation speed, and torque showed obvious data mutation phenomenon, but the flushing fluid pressure did not appear in this place. Through the above analysis, it can be seen that the drilling data not only can predict the stratum structure and strength within a certain range but also can predict the special rock structure or interlayer in the stratum structure. The monitoring results of the changes of various parameters in the remaining boreholes show that the change law is the same as that of borehole 2, indicating that the above analysis results apply to the weathered granite formation in this experiment. Due to the length of the paper, the process curves of other boreholes are not shown here.

\section{Statistics of Field Test Results}

4.1. Statistical Results of Rock Classification and Compressive Strength. Through in-situ tests and coring tests on several typical boreholes on-site, the compressive strength values of different strength grades of rock and soil are recorded, and corresponding rock classifications are made according to the degree of weathering of the rock and soil. The geotechnical classification results and compressive strength results of rock and soil masses with different weathering degrees are statistically calculated. The statistical results are shown in Table 7.

According to on-site test results, the stratigraphic sequence corresponding to different boreholes is slightly different. Some boreholes include overlying alluvial fill, artificial concrete interlayer, and rock veins. According to the field test results and the standard classification of rock strength, it can be classified into grade VI, grade IV, and grades II/I.

4.2. Statistic Results of Drilling Rig Parameters for Different Holes. The field drilling results show that the weathering degree of granite in the stratum with different depths is not used, but the stratum staggered phenomenon is less. Through the five main monitoring parameters of axial pressure, rotation speed, flushing pressure, drilling rate, and torque, combined with the uniaxial compressive strength and rock classification results obtained from field tests, a total of five typical drilling data are selected for analysis.

From the monitoring results in Figures 3 to 8, the variation amplitude and frequency of the perforation rate, axial pressure, rotation speed, and other curves with displacement are relatively large, which shows that the system parameters are highly sensitive to formation recognition. However, it is worth noting that, for rocks of the same strength level, there are still data jumps in the drilling rig parameters. If only the instantaneous parameters at a certain time point are used for analysis, this will easily lead to data irrationality. In fact, in geotechnical engineering, the division of engineering rock mass pays more attention to timeliness and operability, and it is unnecessary and impossible to divide too finely. Therefore, in the following analysis, the method of averaging the borehole parameters is used for statistics, and the segmentation is based on the stratum classification results (this can be seen in Table 7). For example, in a certain section of the stratum, the rock grading standard is of grade IV, and the corresponding core range is $-15.8 \mathrm{~m}$ to $-17.2 \mathrm{~m}$; then the axial pressure shall be the average value of the drilling rig in this displacement range. The statistical calculation results of different boreholes are shown in Tables 8 to 12 .

Drill hole 1 is a typical granite formation, which does not contain fills, artificial concrete, and other formations, but there is a rock vein interlayer at the bottom of the drill hole. Drilling data statistics show that the axial pressure is significantly positively correlated with the rock classification results (i.e., it increases with the increase of rock strength grade), while the drilling rate is negatively correlated, and the flushing fluid pressure overall shows a weaker positive correlation. The rotation speed and torque show a positive correlation when the rock strength grade is low, and there is no obvious law when the rock classification result is high.

The part of borehole 2 above $-5.5 \mathrm{~m}$ has a $1.4 \mathrm{~m}$ thick fill, which can be classified into grade VI according to the rock strength classification standard. There is a concrete interlayer at $-5.5 \mathrm{~m}$ to $-6.2 \mathrm{~m}$, which is divided into grade IV according to the strength grade. From $-33.6 \mathrm{~m}$ to $-34.7 \mathrm{~m}$, there is a rock dike interlayer, which is divided into levels II/I according to the strength level. Also, there is no grade III rock mass in the borehole, and the other parameters are roughly the same as borehole 1 . 
TABle 8: Drilling parameters of hole 1.

\begin{tabular}{|c|c|c|c|c|c|c|}
\hline $\begin{array}{l}\text { Rock } \\
\text { classification }\end{array}$ & $\begin{array}{c}\text { Compressive strength } \\
(\mathrm{MPa})\end{array}$ & $\begin{array}{l}\text { Axial pressure } \\
(\mathrm{kN})\end{array}$ & $\begin{array}{l}\text { Rotation speed } \\
\text { (rad) }\end{array}$ & $\begin{array}{l}\text { Flushing fluid pressure } \\
\text { (MPa) }\end{array}$ & $\begin{array}{l}\text { Drilling rate } \\
\left(\mathrm{cm} \cdot \mathrm{min}^{-1}\right)\end{array}$ & $\begin{array}{l}\text { Torque } \\
(\mathrm{kN} \cdot \mathrm{m})\end{array}$ \\
\hline VI (fill) & - & - & - & - & - & - \\
\hline V & 0.629 & 0.982 & 95 & 0.062 & 35.2 & 0.3125 \\
\hline $\mathrm{V} / \mathrm{IV}$ & 13.76 & 1.168 & 130 & 0.076 & 28.6 & 0.3759 \\
\hline IV (concrete) & - & - & - & - & - & - \\
\hline IV & 31.65 & 2.615 & 145 & 0.181 & 12.5 & 0.8126 \\
\hline IV/III & 48.16 & 3.268 & 287 & 0.384 & 11.2 & 1.3591 \\
\hline III & 56.53 & 3.892 & 230 & 0.297 & 15.4 & 1.3486 \\
\hline III/II & 79.635 & 4.165 & 245 & 0.364 & 10.3 & 1.5267 \\
\hline II & 97.653 & 4.325 & 310 & 0.341 & 4.6 & 1.6015 \\
\hline II/I (vein) & 114.6 & 3.894 & 278 & 0.433 & 3.3 & 1.4569 \\
\hline
\end{tabular}

TABle 9: Drilling parameters of hole 2.

\begin{tabular}{|c|c|c|c|c|c|c|}
\hline $\begin{array}{l}\text { Rock } \\
\text { classification }\end{array}$ & $\begin{array}{c}\text { Compressive strength } \\
(\mathrm{MPa})\end{array}$ & $\begin{array}{c}\text { Axial pressure } \\
(\mathrm{kN})\end{array}$ & $\begin{array}{l}\text { Rotation speed } \\
\text { (rad) }\end{array}$ & $\begin{array}{l}\text { Flushing fluid pressure } \\
\qquad(\mathrm{MPa})\end{array}$ & $\begin{array}{l}\text { Drilling rate } \\
\left(\mathrm{cm} \cdot \mathrm{min}^{-1}\right)\end{array}$ & $\begin{array}{l}\text { Torque } \\
(\mathrm{kN} \cdot \mathrm{m})\end{array}$ \\
\hline VI (fill) & 0.089 & 1.231 & 88 & 0.115 & 45.5 & 0.4026 \\
\hline $\mathrm{V}$ & 0.758 & 1.593 & 122 & 0.088 & 39.8 & 0.5136 \\
\hline V/IV & 13.37 & 2.136 & 96 & 0.169 & 22.9 & 0.8416 \\
\hline IV (concrete) & 28.47 & 1.873 & 132 & 0.196 & 19.6 & 0.8106 \\
\hline IV & 38.65 & 2.395 & 71 & 0.245 & 11.9 & 0.9687 \\
\hline IV/III & 52.54 & 2.486 & 78 & 0.336 & 17.3 & 1.0312 \\
\hline III & - & - & - & - & - & \\
\hline III/II & 76.369 & 2.893 & 165 & 0.268 & 10.3 & 1.13621 \\
\hline II & 99.163 & 5.425 & 278 & 0.361 & 4.9 & 1.4896 \\
\hline II/I (vein) & 117.8 & 4.962 & 225 & 0.268 & 2.8 & 1.7169 \\
\hline
\end{tabular}

TABLe 10: Drilling parameters of hole 3.

\begin{tabular}{|c|c|c|c|c|c|c|}
\hline $\begin{array}{l}\text { Rock } \\
\text { classification }\end{array}$ & $\begin{array}{c}\text { Compressive strength } \\
(\mathrm{MPa})\end{array}$ & $\begin{array}{l}\text { Axial pressure } \\
(\mathrm{kN})\end{array}$ & $\begin{array}{l}\text { Rotation speed } \\
\quad(\mathrm{rad})\end{array}$ & $\begin{array}{l}\text { Flushing fluid pressure } \\
(\mathrm{MPa})\end{array}$ & $\begin{array}{l}\text { Drilling rate } \\
\left(\mathrm{cm} \cdot \mathrm{min}^{-1}\right)\end{array}$ & $\begin{array}{l}\text { Torque } \\
(\mathrm{kN} \cdot \mathrm{m})\end{array}$ \\
\hline VI (fill) & - & - & - & - & - & \\
\hline $\mathrm{V}$ & 0.626 & 2.665 & 79 & 0.106 & 35.3 & 0.715 \\
\hline V/IV & 16.37 & 3.063 & 122 & 0.156 & 29.6 & 0.8975 \\
\hline IV (concrete) & - & - & - & - & - & \\
\hline IV & 28.75 & 2.689 & 99 & 0.264 & 17.5 & 1.0548 \\
\hline IV/III & 56.28 & 3.706 & 158 & 0.367 & 19.8 & 1.2354 \\
\hline III & 67.27 & 4.612 & 216 & 0.348 & 12.5 & 1.3679 \\
\hline III/II & 82.781 & 5.216 & 179 & 0.374 & 9.8 & 1.4685 \\
\hline II & - & - & - & - & - & - \\
\hline II/I (vein) & - & - & - & - & - & - \\
\hline
\end{tabular}

TABLE 11: Drilling parameters of hole 4.

\begin{tabular}{|c|c|c|c|c|c|c|}
\hline $\begin{array}{l}\text { Rock } \\
\text { classification }\end{array}$ & $\begin{array}{c}\text { Compressive strength } \\
(\mathrm{MPa})\end{array}$ & $\begin{array}{l}\text { Axial pressure } \\
(\mathrm{kN})\end{array}$ & $\begin{array}{l}\text { Rotation speed } \\
\quad(\mathrm{rad})\end{array}$ & $\begin{array}{l}\text { Flushing fluid pressure } \\
(\mathrm{MPa})\end{array}$ & $\begin{array}{l}\text { Drilling rate } \\
\left(\mathrm{cm} \cdot \mathrm{min}^{-1}\right)\end{array}$ & $\begin{array}{l}\text { Torque } \\
(\mathrm{kN} \cdot \mathrm{m})\end{array}$ \\
\hline VI (fill) & - & - & - & - & - & - \\
\hline $\mathrm{V}$ & 0.648 & 1.269 & 102 & 0.098 & 42.6 & 0.7156 \\
\hline $\mathrm{V} / \mathrm{IV}$ & 14.29 & 1.624 & 116 & 0.134 & 29.8 & 0.7958 \\
\hline IV (concrete) & - & - & - & - & - & - \\
\hline IV & 30.68 & 2.968 & 126 & 0.219 & 15.6 & 1.1789 \\
\hline IV/III & 51.52 & 2.189 & 158 & 0.394 & 18.6 & 0.9136 \\
\hline III & 64.98 & 4.267 & 263 & 0.289 & 17.1 & 1.5136 \\
\hline III/II & 88.263 & 3.489 & 215 & 0.269 & 9.2 & 1.3512 \\
\hline II & 105.265 & 6.152 & 324 & 0.327 & 3.6 & 2.1893 \\
\hline II/I (vein) & - & - & - & - & - & - \\
\hline
\end{tabular}


TABLE 12: Drilling parameters of hole 5.

\begin{tabular}{|c|c|c|c|c|c|c|}
\hline $\begin{array}{l}\text { Rock } \\
\text { classification }\end{array}$ & $\begin{array}{c}\text { Compressive strength } \\
(\mathrm{MPa})\end{array}$ & $\begin{array}{c}\text { Axial pressure } \\
(\mathrm{kN})\end{array}$ & $\begin{array}{l}\text { Rotation speed } \\
\text { (rad) }\end{array}$ & $\begin{array}{l}\text { Flushing fluid pressure } \\
(\mathrm{MPa})\end{array}$ & $\begin{array}{l}\text { Drilling rate } \\
\left(\mathrm{cm} \cdot \mathrm{min}^{-1}\right)\end{array}$ & $\begin{array}{l}\text { Torque } \\
(\mathrm{kN} \cdot \mathrm{m})\end{array}$ \\
\hline VI (fill) & - & - & - & - & - & - \\
\hline $\mathrm{V}$ & 0.598 & 2.016 & 101 & 0.071 & 33.1 & 0.9487 \\
\hline $\mathrm{V} / \mathrm{IV}$ & 15.478 & 2.614 & 113 & 0.092 & 26.8 & 1.0346 \\
\hline IV (concrete) & - & - & - & - & - & - \\
\hline IV & 33.145 & 3.186 & 91 & 0.179 & 13.9 & 1.3485 \\
\hline IV/III & 53.487 & 4.135 & 213 & 0.317 & 15.8 & 1.5036 \\
\hline III & 66.142 & 3.549 & 271 & 0.327 & 11.1 & 1.3948 \\
\hline III/II & 87.457 & 3.918 & 243 & 0.297 & 9.3 & 1.4362 \\
\hline II & 102.435 & 5.487 & 304 & 0.384 & 5.1 & 1.8956 \\
\hline II/I (vein) & 109.469 & 4.156 & 269 & 0.415 & 2.9 & 1.6012 \\
\hline
\end{tabular}

The survey results of borehole 3 show that the corresponding stratum structure of the borehole is relatively simple. The weathering grade of granite ranges from grade $\mathrm{V}$ to grades III/II, and there is no special formation such as fill, concrete, and rock veins. However, compared with other boreholes, the axial pressure in this borehole has obvious characteristics of larger value and weaker regularity. The perforation rate is generally and negatively correlated with the results of rock mass classification, but some strata with higher rock classification have faster perforation rates. Based on the analysis of these two data, the stratum drilled by the borehole should belong to the more complicated weathered granite stratum.

The survey results of the stratum corresponding to borehole 4 show that the corresponding rock classification and compressive strength of the stratum have obvious regularities and do not include concrete interlayers and rock vein interlayers. It is especially worth noting that the drill bit speed is positively correlated with the rock classification law and compressive strength, which is not obvious in another drilling. The compressive strength of rock mass has a strong correlation with drilling rate and axial pressure, and the correlation between flushing fluid pressure is not obvious.

The stratum statistics of drill hole 5 are similar to drill hole 1 . The rock mass classification results range from grade $\mathrm{V}$ to II/I. The big difference is that the central axis pressure of the drill hole is generally higher, which may be related to the working habits of the drill rig operator.

\section{The Relationship between Drilling Rig Parameters and Rock Classification and Compressive Strength}

It can be seen from the law of the above chart analysis that there is a certain degree of correlation between the fieldbased drilling monitoring parameters and the formation classification results and compressive strength. This part will analyze the axial pressure, rotation speed, flushing fluid pressure, drilling rate, and torque obtained on-site and use regression analysis to establish the regression equation between drilling parameters and strata classification and compressive strength.

According to the monitoring results of different boreholes, the rock grade, compressive strength, and corresponding drilling monitoring parameters are analyzed separately, the origin software is used for fitting, and the result with the best fitting effect is selected. The relationship between rock classification results and uniaxial compressive strength distribution is shown in Figure 9. It can be seen from the figure that, as the grade of the rock increases, the uniaxial compressive strength gradually increases. The correlation between the two is obvious and the classification result is reasonable. Figures 10 to 14 are the scattered diagrams of axial pressure, drill bit speed, flushing pressure, perforation rate, and torque, rock classification, and compressive strength, respectively, and the corresponding fitting formulas are marked in the figure.

\section{Rock Classification and Compressive Strength Prediction Based on Drilling Parameters}

From the scattered plots and fitting equations of different parameters and rock classification and uniaxial compressive strength in the five boreholes, it can be seen that the axial pressure, rotation speed, flushing fluid pressure, drilling rate, and torque are all equal to the rock strength. There is a certain functional relationship. Among them, the four parameters other than the drilling rate are all positively related to the rock grading and uniaxial compressive strength; that is to say, they all increase with the increase of the rock strength grade, and the drilling rate shows an increase and decrease. The perforation rate is the most intuitive indicator reflecting the difficulty of rock drilling in engineering. Generally speaking, the stronger the rock and soil, the slower the drilling speed. This is consistent with the results of this field test. In this experiment, it is found that the perforation rate has an approximately exponential function relationship with the rock strength classification result and an approximately linear function relationship with the compressive strength.

It is worth noting that, in the formation where the rock classification result is IV, the penetration rate has a more obvious numerical sudden change (jump point). The main reason is that the concrete interlayer appeared in some drilling holes, which were classified into grade IV rocks according to the classification standards, which resulted in different perforation speeds of rocks of the same strength grade. This phenomenon also appears in the scattered plots 


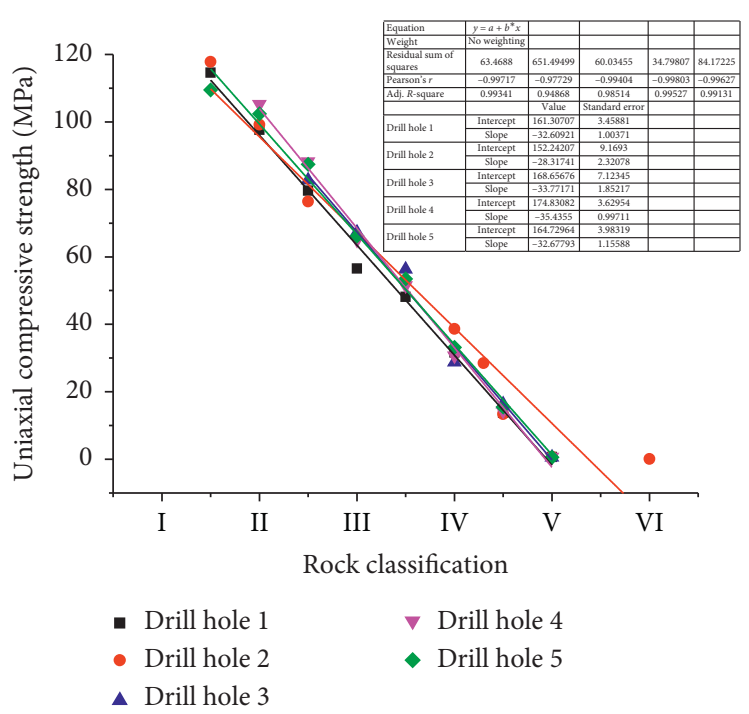

FIgURE 9: The relationship between uniaxial compressive strength and rock classification.

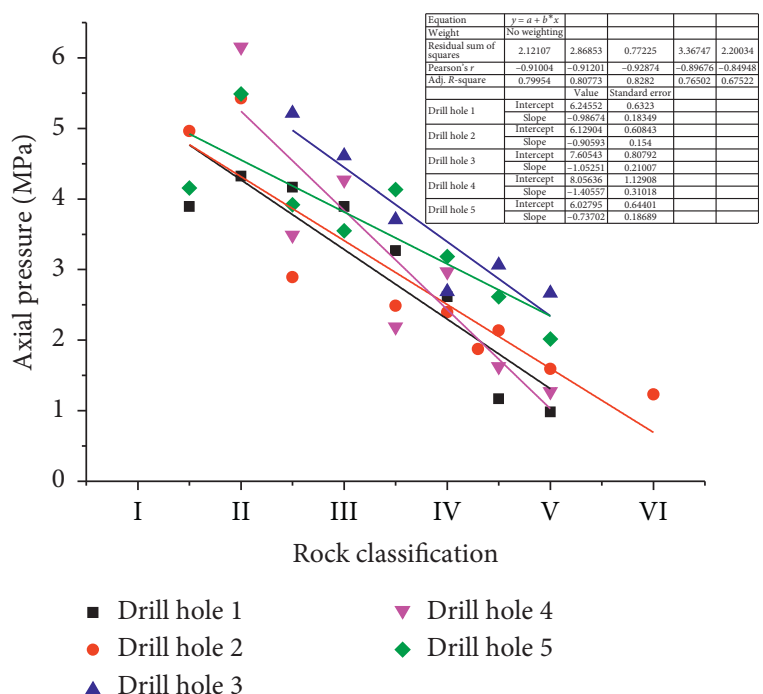

(a)

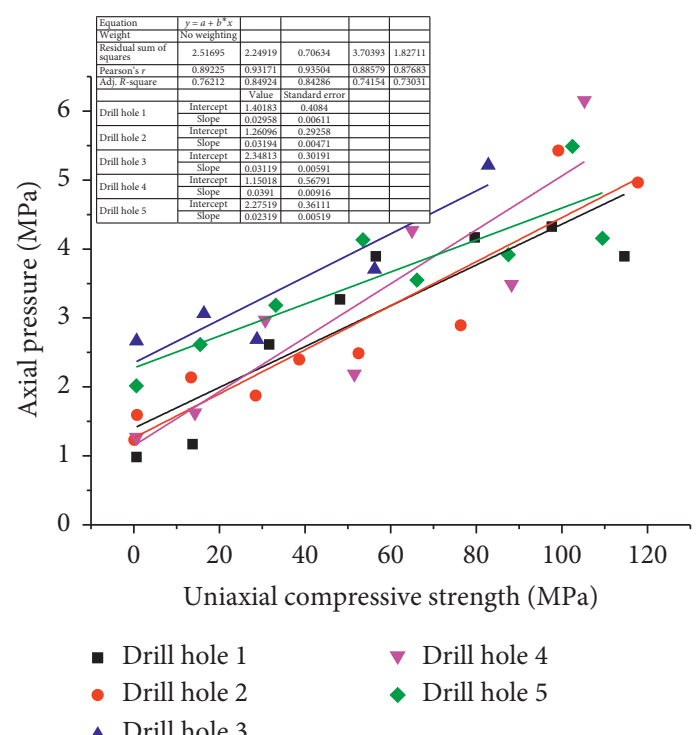

(b)

FIGURE 10: Relationship between rock classification, compressive strength, and axial pressure.

of other parameters. For example, in the flushing pressure of grades IV/III rock (compressive strength about 50-60 MPa), the scattered diagram of perforation rate, and compressive strength of fill (compressive strength about $0.06 \mathrm{MPa}$ ), a similar "jump point" also appears. This will bring certain difficulties to the classification of rock grades, which should be paid attention to in future research.

According to the previous analysis, it is feasible to realize the identification of different weathered granite formations through drilling parameters in this test. Perform statistical analysis on 5 drilling data parameters and get the regression relationship between rock classification, compressive strength index, and different drilling parameters. The specific regression equation is shown in Table 13.

In the table, RMC represents the result of rock classification. The values 1-6 in this formula correspond to I-VI, respectively; $\sigma_{c}$ represents the uniaxial compressive strength.

The coefficient of determination $R^{2}$ is a relative indicator of the goodness of fit between the regression line and the sample observations, reflecting the proportion of the dependent variable that can be explained by the independent variable, $0<R^{2}<1$. Generally, when the coefficient of determination is closer to 1 , the majority of the uncertainty of the dependent variable can be explained by the regression 


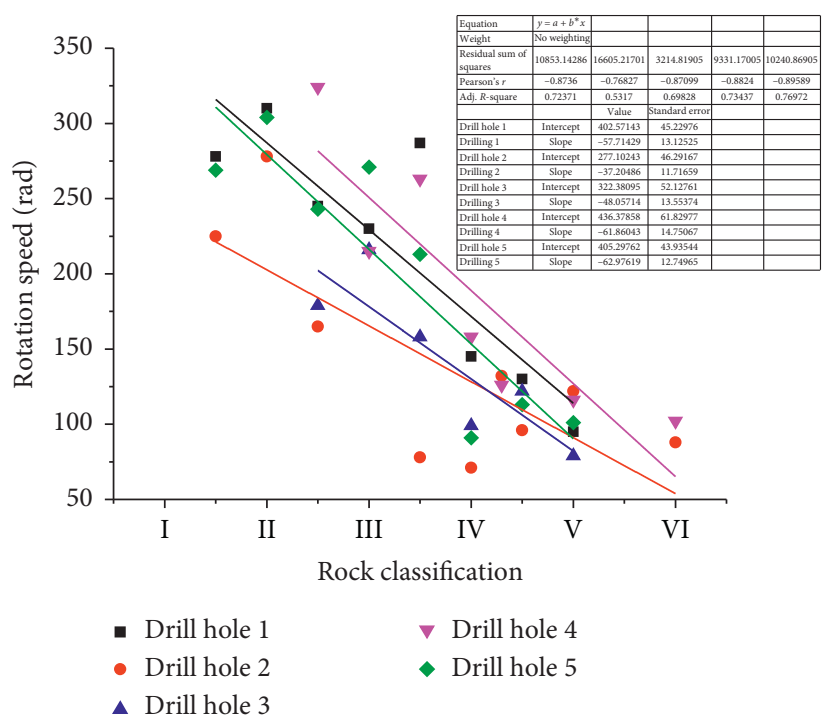

(a)

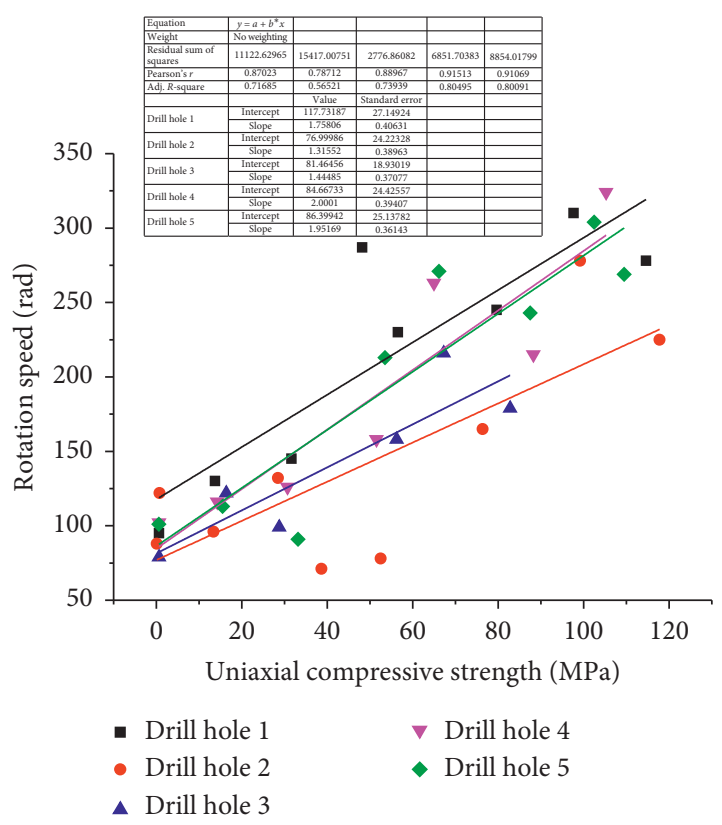

(b)

FIGURE 11: Relationship between rock classification, compressive strength, and bit rotation speed.

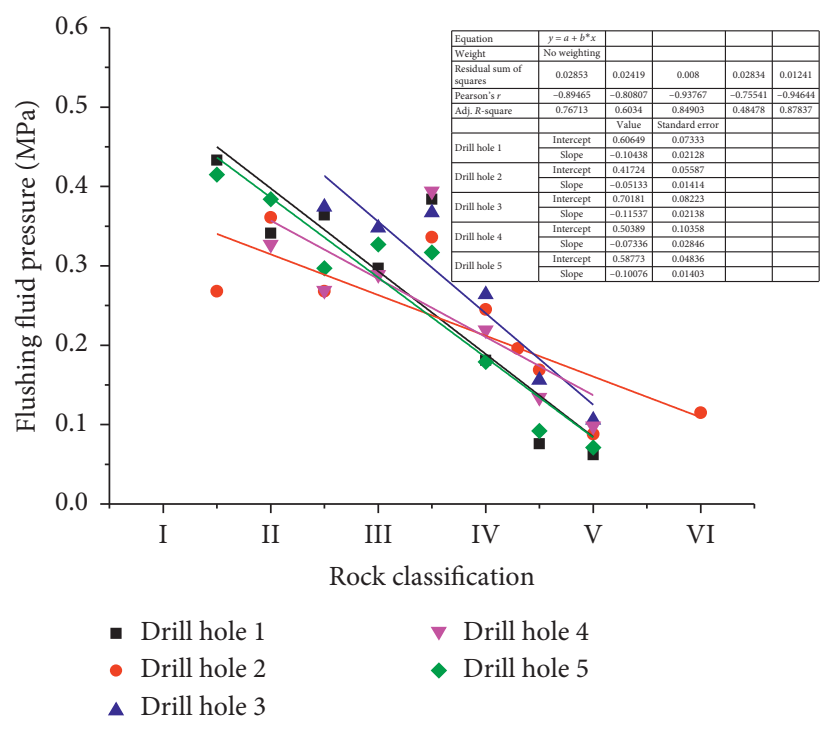

(a)

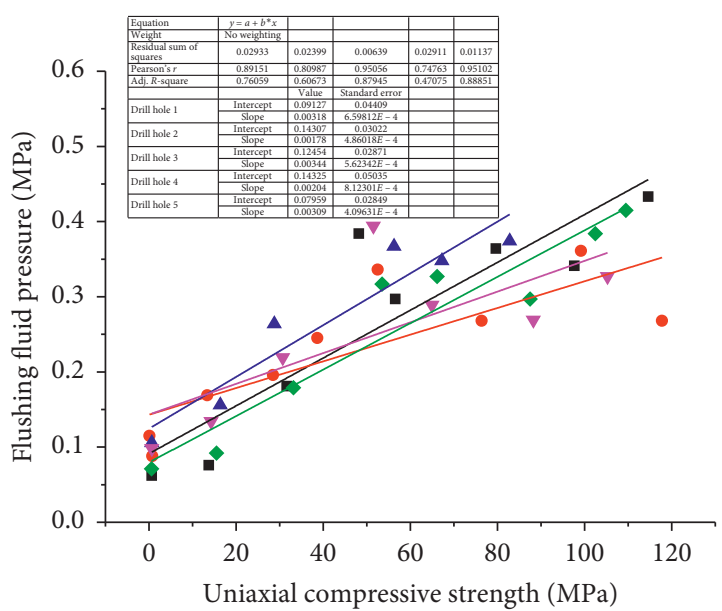

- Drill hole 1

- Drill hole 2

- Drill hole 3

FIgURE 12: Relationship between rock classification, compressive strength, and flushing fluid pressure.

equation. The goodness of the regression equation is better. Otherwise, the effect is not good and should be modified. It can be seen from the above fitting relationship that the degree of correlation between the five drilling parameters and the rock grade in descending order is the drilling rate $\left(v_{p}\right)$, axial pressure $\left(F_{e}\right)$, torque $\left(M_{d}\right)$, rotation speed $\left(r_{v}\right)$, and flushing pressure $\left(F_{w}\right)$. Among them, the perforation rate has the highest correlation with the rock classification and compressive strength (greater than 0.8), the axial pressure, torque, and rotation speed which have a close correlation (about 0.7 ), and the flushing fluid pressure has a low correlation (about 0.6 ).

It is worth noting that, from Figures 10 to 14, some parameters have reached a fairly high accuracy in the prediction of a certain borehole. For example, the correlation coefficient $R^{2}$ of torque and compressive strength in borehole 2 is 0.94 , which can fully meet the rock mass classification standard in engineering investigation. However, 


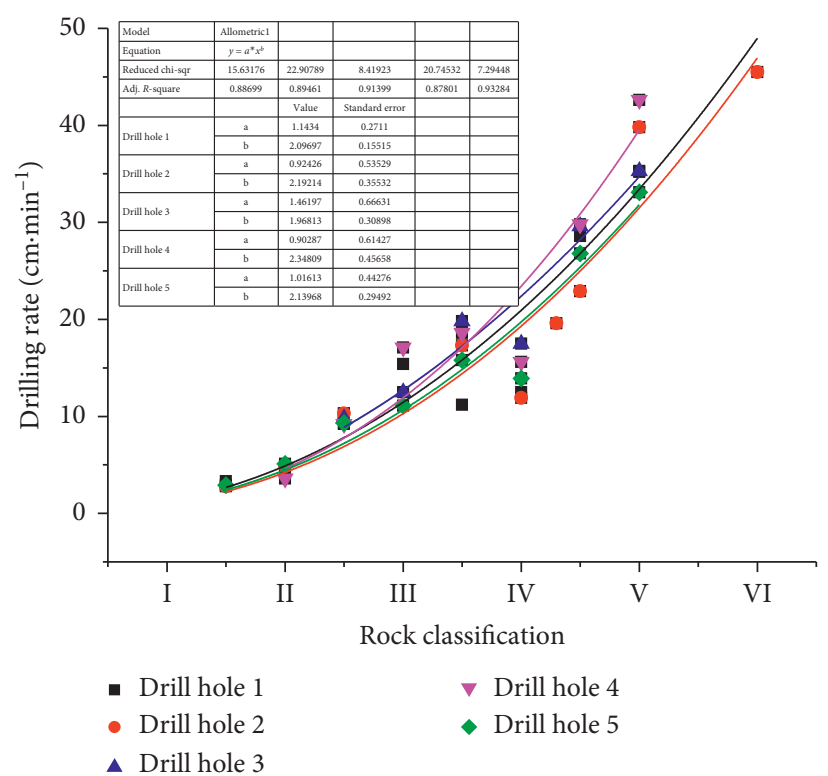

(a)

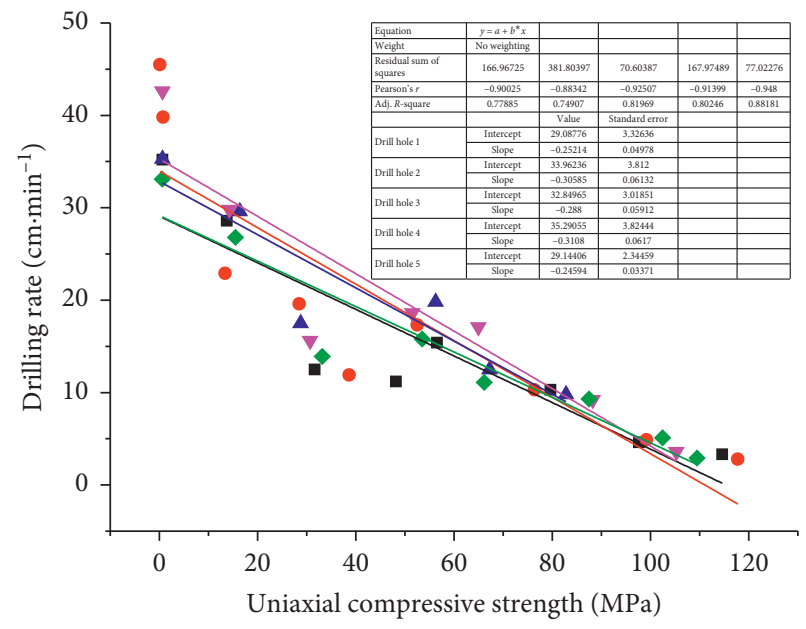

- Drill hole 1

- Drill hole 2

$\checkmark$ Drill hole 4

- Drill hole 5

FIGURE 13: Relationship between rock classification, compressive strength, and drilling rate.

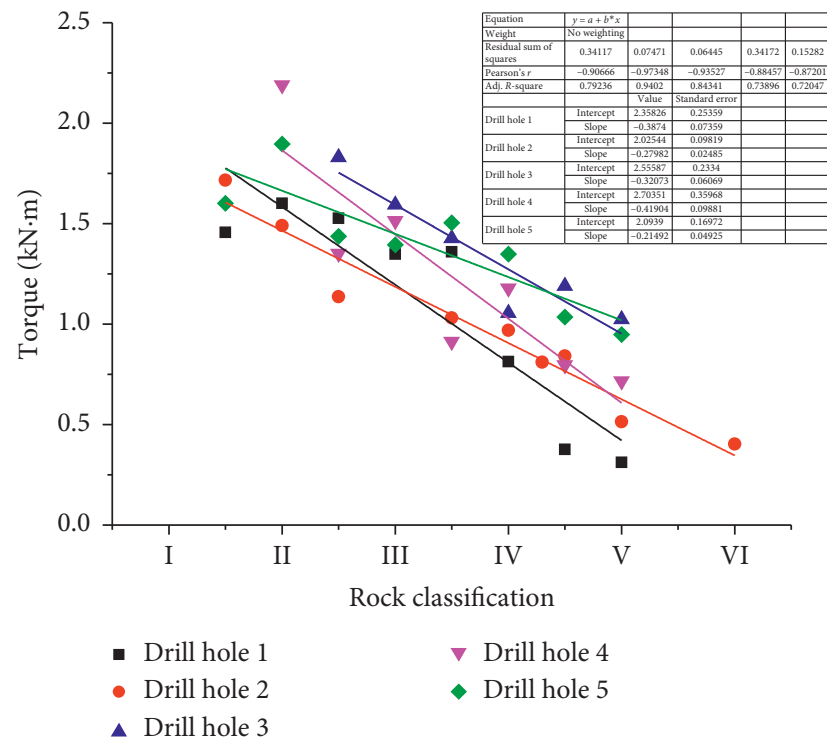

(a) $\nabla$ Drill hole 4
- Drill hole 5

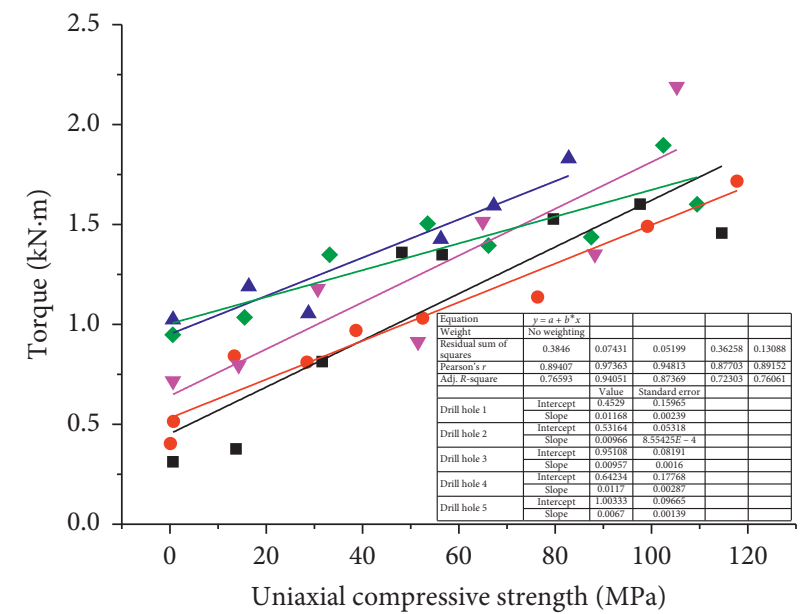

- Drill hole 1

- Drill hole 2

A Drill hole 3 $\checkmark$ Drill hole 4

Drill hole 5

(b)

(b)

FIGURE 14: Relationship between rock classification, compressive strength, and torque.

TABLE 13: Rock classification and strength prediction model based on drilling parameters.

\begin{tabular}{|c|c|c|c|c|}
\hline \multirow{2}{*}{ Drilling parameters } & \multicolumn{2}{|l|}{ Rock classification } & \multicolumn{2}{|c|}{ Compressive strength $(\mathrm{MPa})$} \\
\hline & Formula & $R^{2}$ & Formula & $R^{2}$ \\
\hline Axial pressure & $\mathrm{RMC}=5.90834-0.75419 F_{e}$ & 0.75 & $\sigma_{c}=-26.83255+24.25226$ & 0.74 \\
\hline Rotation speed & $\mathrm{RMC}=5.78303-0.01242 r_{v}$ & 0.69 & $\sigma_{c}=0.39781 r_{v}-19.32303$ & 0.71 \\
\hline Flushing fluid pressure & $\mathrm{RMC}=5.68366-8.70658 F_{w}$ & 0.53 & $\sigma_{c}=0.12256-0.00255 F_{w}$ & 0.59 \\
\hline Drilling rate & $\mathrm{RMC}=1.00694 v_{p}^{0.45044}$ & 0.87 & $\sigma_{c}=102.34787-2.87877 v_{p}$ & 0.83 \\
\hline Torque & $\mathrm{RMC}=1.57232-3.78795 \times 0.10763^{E_{d}}$ & 0.74 & $\sigma_{c}=-35.4704+72.15778 M_{d}$ & 0.72 \\
\hline
\end{tabular}


when comprehensively analyzing the data of five boreholes, it is found that the correlation coefficients of torque and rock strength classification and compressive strength are only 0.74 and 0.71 , respectively. This shows that the geological environment of different boreholes is quite different and reflects the complexity of the underground environment. The factors that affect drilling rig parameters are not only the shear strength of the rock and soil, but also the modulus of elasticity, Poisson's ratio, and coefficient of friction. For the same drilling, the habits of different operators will also affect the drilling rig parameters. Therefore, a prediction model that only considers a drilling parameter will have a large discrete problem, and it is difficult to reflect the real situation of the formation. To solve this problem, the method of calculating multiple parameters together will be used to provide analyzsis from the perspective of drilling specific energy.

\section{Rock Classification and Strength Prediction Based on Drilling Specific Energy}

The chipping specific energy was first proposed by Teale [41], and its meaning is the energy required to break a unit volume of rock, which is usually measured by the chipping method in the laboratory. Crushing specific energy can be used to classify rock drillability, and some scholars have also extended this method to the prediction of rock strength and the prediction of special underground structures [11, 33, 45-48]. Theoretically, the drilling speed, axial pressure, torque, and other drilling parameters of the same type of drill and bit should be a constant [24]. The energy equation established by this method can be well verified in the laboratory under the ideal state. However, compared with the laboratory, due to more complex and changeable geological environment, it is difficult to keep the force and power exerted by the drilling rig on the rock mass constant during the drilling process, which will also lead to the jumping phenomenon of drilling parameters. Some scholars changed their thinking and directly used the method of drilling rig output power for calculation, that is, calculating according to the work done by the drilling rig hydraulic motor and hydraulic pressure, and achieved certain results [48]. However, the output power of the drilling rig includes not only the energy used for rock crushing but also the energy consumed by the displacement and friction of the drilling rig itself. As the drilling depth increases, the proportion of this energy in the output energy of the drilling rig will gradually increase. This part of the content changes ideas, adopts the principle of energy conservation and transformation, and regards the drilling rig system as a mass point system, avoiding the limitations of the above problems and exploring the law of energy distribution of the drilling rig during the drilling process and the relationship with the formation information.

There are two common forms of drilling damage, one is percussion drilling, and the other is rotary drilling. The mechanism of percussion drilling is that the hammer carries the drill bit down from a certain height and uses kinetic energy to break the rock mass. For rotary drilling, the energy of rock breaking mainly comes from the effective axial pressure exerted by the drill bit on the rock mass and the torque generated by the rotation of the drill bit. Effective axial pressure can ensure that the drill bit is always in contact with the rock mass and can press the bit into a certain depth of rock mass. At the same time, the low shear strength of the rock mass is used to make the rock mass cut under the action of torque to achieve rock breaking. These two parts of energy are used for not only rock crushing, but also frictional heat generation, crushing, and sound generation during drilling. Regarding the drilling system as a mass point system, according to the principle of conservation of energy, the power system of the drilling rig has the following energy conversion relationship [54]:

$$
P_{e}=P_{k}+P_{d}+P_{f}
$$

where $P_{e}$ is the total energy output by the power system of the drilling rig; $P_{k}$ is the kinetic energy generated by the rotary motion of the drill pipe and the drill bit; $P_{d}$ is the work done by the drill pipe and the drill bit to overcome the gravity displacement and press into the rock; $P_{f}$ is the internal friction during the rotation or energy output of the drill or the energy consumed by vibration.

Obviously, the energy used for drilling rock fragmentation mainly comes from the kinetic energy $P_{k}$ generated by the rotation of the drilling tool, and the work $P_{d}$ done by the effective shaft pressure; $P_{f}$ does not directly affect the process of rock breaking, so the total energy $P_{w}$ consumed in the drilling process is

$$
P_{w}=P_{k}+P_{d}
$$

The kinetic energy $P_{k}$ generated by the rotary motion of the drilling tool and the work $P_{d}$ done to overcome the gravity is related to the quality of the drilling tool. As the drilling depth increases, its size will also increase; then,

$$
\begin{aligned}
& P_{k}=\frac{1}{2}\left(\sum m\right) V_{1}^{2}=\frac{1}{2}\left(\sum m\right)\left(\pi D r_{v}\right)^{2}, \\
& P_{d}=\left(F_{t}+\sum m g-F_{a}\right) S \sin \alpha=F_{e} v_{p} \sin \alpha,
\end{aligned}
$$

where $\sum m$ is the sum of the quality of the drilling system, which is related to the depth of the hole; $V_{1}$ is the instantaneous linear velocity of the drilling system; $D$ is the gyration radius of the drilling system; $r_{v}$ is the rotation speed of the drill bit; $F_{e}$ is the effective axis on the drill pipe pressure, and $F_{a}$ are the forces of the pressurizing system and the pressure regulating system of the drilling tool system; $S$ is the displacement of the drill bit per unit time; $v_{p}$ is the perforation rate; $\alpha$ is the angle between the central axis of the drill pipe system and the horizontal plane. The range is $0^{\circ} \leq$ $\alpha \leq 90^{\circ}$; when it is vertical drilling, take $\alpha=90^{\circ}$.

The main form of $P_{k}$ broken rock in the above analysis is the rock friction effect between the drill bit and the bottom of the borehole and the hole wall, which generates heat while achieving the purpose of rock crushing. In unit time, the energy $P_{f, d}$ consumed by the friction between the drill bit and the hole bottom and the energy $P_{f, c}$ consumed by the lateral friction with the hole wall are 


$$
\begin{aligned}
& P_{f, d}=\frac{1}{4} \int_{0}^{\theta} r_{v} \tau_{f} D_{b} \mathrm{~d} \theta=\frac{1}{4} r_{v} \mu_{b} \pi D_{b} F_{e}, \\
& P_{f, c}=\pi D_{b} \mu_{c} K_{c} F_{e} r_{v},
\end{aligned}
$$

where $\tau_{f}$ is the friction stress at the bottom of the hole; $\mu_{b}$ is the coefficient of friction between the drill bit and the rock at the bottom of the hole; $D_{b}$ is the outer diameter of the drill bit. When drilling with a coring bit, take the average of the inner and outer diameters; when drilling with a destructive bit, take half of the outer diameter of the bit; $\mu_{c}$ is the friction coefficient between the drill tool and the hole wall rock; $K_{c}$ is the lateral pressure coefficient, which is related to Poisson's ratio of the rock.

It is not difficult to find that the total energy in (5) and (6) is the energy mainly used to break the rock during the rotation of the drill bit. However, there are some parameters that are difficult to measure and will change with the characteristics of rock, such as the friction coefficient at the bottom of hole, the friction coefficient at the wall of hole, and the Poisson's ratio. Therefore, it is necessary to convert this energy into a calculable value. In this test, a torque-based energy calculation method can be used for conversion. The torque work $P_{m}$ per unit time is

$$
P_{m}=2 \pi M_{d} r_{v}
$$

where $M_{d}$ is the torque during drilling; $r_{v}$ is the speed during drilling.

Torque work and axial force work are used for rock breaking, and part of the energy is used for the hoop and axial friction between drill pipes (including drill pipes and connecting rods) and drilling fluid. The energy consumption of hoop friction between the drill pipe and drilling fluid per unit time $P_{h}$ and axial friction energy consumption $P_{a}$ is, respectively,

$$
\begin{aligned}
& P_{h}=\mu_{h} N_{h} \pi D_{r} r_{v}, \\
& P_{a}=\mu_{a} N_{a} \pi v_{p},
\end{aligned}
$$

where $\mu_{h}$ is the friction factor between the drill pipe and the drilling fluid when the drill pipe is rotating; $\mu_{a}$ is the friction factor between the drill pipe and the drilling fluid when the drill pipe moves in the axial direction; $N_{h}$ is the viscosity between the drill pipe and the drilling fluid when the drill pipe moves in the circumferential direction. Stagnation force: $N_{a}$ is the viscous force between the drill pipe and the drilling fluid when the drill pipe moves axially, and $N_{h}=N_{a} ; D_{r}$ is the drill pipe's outer diameter.

It can be seen from the above analysis that these two parts of energy are not used for rock breaking but are mainly used to overcome the resistance of the drilling fluid and convert it into kinetic energy and heat energy of the drilling fluid. The measurement of energy conversion between the drill pipe and drilling fluid is very complicated and cannot be accurately obtained through theoretical or experimental analysis. Because the distance between the drill pipe and the hole wall is small, the liquid particles between the pores can be considered to move at the same linear velocity as the drill pipe rotation speed. Therefore, it can be considered that the hoop friction energy consumption $P_{h}$ of the drill pipe is completely transformed into the kinetic energy $P_{l}$ of the drilling fluid; then formula (8) can be transformed into

$$
\begin{aligned}
P_{h} & =P_{l}=\frac{1}{2} m_{1} V_{1}^{2} \\
& =\frac{1}{2} \rho v_{p} \pi\left[\left(\frac{D_{b}}{2}\right)^{2}-\left(\frac{D_{r}}{2}\right)^{2}\right]\left(\pi D_{e} r_{v}\right)^{2} \\
& =\frac{1}{108} \rho v_{p} \pi^{3}\left(D_{b}^{2}-D_{r}^{2}\right) \cdot\left(D_{b}+D_{r}\right)^{2} r_{v}^{2},
\end{aligned}
$$

where $\rho$ is the density of the drilling fluid; $D_{e}$ is the equivalent diameter of the annular column of the drilling fluid, taking the position from the midpoint of the distance between the drill bit and the drill pipe to the center of the hole.

For drill pipe and hoop direction, in actual drilling engineering, the drilling speed is very small, so the viscous force of drilling fluid on the drill pipe is also very small, so the energy in (9) can be ignored.

Based on the principle of energy conservation, the energy $P_{r f}$ used to drill into the broken rock is

$$
P_{r f}=P_{w}-P_{h}-P_{a} \approx P_{m}+P_{d}-P_{h}=P_{m}+P_{d}-P_{l} .
$$

According to the physical meaning of crushing specific energy, the drilling specific energy $E_{d}$ required in this test is defined as

$$
E_{d}=\frac{P_{e}}{V}
$$

In this formula, $P_{e}$ is the energy required for rock breaking per unit time, which is equivalent to $P_{r f}$ in value; $V$ is the volume of rock broken per unit time.

Substituting formulas (4), (7), (10), and (11) into formula (12), then

$$
E_{d}=\frac{216 \pi M_{d} r_{v}+108 F_{e} v_{p}-\rho v_{p} \pi^{3}\left(D_{b}^{2}-D_{r}^{2}\right) \cdot\left(D_{b}+D_{r}\right)^{2} r_{v}^{2}}{54 \pi\left(D_{b}^{2}-D_{i}^{2}\right) v_{p}}
$$

where $M_{d}$ is the torque; $r_{v}$ is the rotation speed; $F_{e}$ is the effective shaft pressure; $v_{p}$ is the drilling rate; $D_{b}$ is the outer diameter of the drill bit; $D_{i}$ is the inner diameter of the drill bit; $\rho$ is the drill pipe diameter; $\mathrm{H}$ is the drilling fluid density. The middle is pure water, $10^{3} \mathrm{~kg} / \mathrm{m}^{3}$.

After the above analysis and transformation, the parameters required for the calculation of the energy consumed in the drilling process have all been transformed into fixed parameters and drilling monitoring parameters. The specific energy value of drilling can be obtained according to the field test results.

According to calculation formula (13) of drilling specific energy established according to the energy principle, the 
specific energy of the strata with different strength levels in the 5 boreholes is calculated and the average value is calculated. The statistical results are shown in Table 14. It can be seen from the table that, as the rock grade or compressive strength increases, the specific energy value of drilling also increases. The same law appeared in the 5 boreholes, which also shows the rationality of the formula. Corresponding with the results of rock grade and uniaxial compressive strength with the calculated specific energy value of drilling, respectively, we draw a scattered diagram as shown in Figure 15. It can be seen from Figure 15 that the drilling specific energy has an exponential function relationship with the rock grade and uniaxial compressive strength and the scattered diagram in the figure shows that the dispersion is small and the prediction accuracy is better.

At the same time, it can be seen from Figure 15 that the drilling specific energy values of different grades of rocks have obvious segmentation rules, which can be divided into four segments in total: when the rock grade is from VI to V/ IV, the drilling specific energy ranges from 0.0214 to $0.1215 \mathrm{kN} \cdot \mathrm{m} \cdot \mathrm{cm}^{-3}$, with an average value of $0.0626 \mathrm{kN} \cdot \mathrm{m} \cdot \mathrm{cm}^{-3}$. When the rock grade is IV to III, the drilling specific energy ranges from 0.2212 to $0.4009 \mathrm{kN} \cdot \mathrm{m} \cdot \mathrm{cm}^{-3}$, with an average value of $0.2952 \mathrm{kN} \cdot \mathrm{m} \cdot \mathrm{cm}^{-3}$. When the rock grade is III/II, the drilling specific energy ranges from 0.6145 to $0.7032 \mathrm{kN} \cdot \mathrm{m} \cdot \mathrm{cm}^{-3}$, with an average value of $0.6592 \mathrm{kN} \cdot \mathrm{m} \cdot \mathrm{cm}^{-3}$. When the rock grade is from II to II/I, the drilling specific energy ranges from 1.1256 to $1.4896 \mathrm{kN} \cdot \mathrm{m} \cdot \mathrm{cm}^{-3}$, and the average value is $1.2915 \mathrm{kN} \cdot \mathrm{m} \cdot \mathrm{cm}^{-3}$. It is worth noting that the above data is the result of averaging the formations. However, due to factors such as rig operator habits and formation crossing, there will be a certain overlap area in the drilling specific work values of different formations. According to the rock classification of the formation and the calculation result of drilling specific work, the classification result of the granite strata structure is shown in Table 15.

In the prediction of drilling specific energy and rock grade, the highest prediction accuracy of a single borehole is borehole 4 , its prediction accuracy is $R^{2}=0.97$, the lowest is borehole 3 , its prediction accuracy is $R^{2}=0.88$, and its comprehensive prediction accuracy is $R^{2}=0.93$. In the prediction of drilling specific energy and rock compressive strength, borehole 2 has the highest prediction accuracy, which has reached $R^{2}=0.99$, and borehole 3 has the lowest prediction accuracy, with prediction accuracy of $R^{2}=0.84$ and comprehensive prediction accuracy of $R^{2}=0.92$. Nonlinear regression will be carried out based on the calculation results of specific drilling work and the results of field measured rock grade and compressive strength. The prediction formula is shown in Table 16.

From the calculation results in Table 16, it can be seen that the rock classification and compressive strength prediction model based on drilling specific work has high accuracy and its $R^{2}$ value is greater than 0.9 , which can be used as a quick and effective method for identification of stratum structure in geotechnical engineering investigation. Through comparison with a single parameter, the rock-soil strength prediction model based on drilling specific work combines multiple parameters for analysis, improving the prediction accuracy, and the result is more reasonable, which is more suitable for practical engineering applications.

\section{Discussion}

Due to the complexity and variability of underground structures, no matter which method is adopted, it is difficult to describe the composition of the stratum structure perfectly. In previous research, many scholars used simulated drilling in the laboratory, but, due to the existence of natural geological environmental factors such as ground stress, pore water pressure, and temperature, the results obtained in the laboratory are compared with the field engineering where there will be large errors. The current research based on the engineering site mostly focuses on the qualitative description of the stratum structure, such as the positioning of underground chambers and weak layers. Judging from the results of parameter monitoring in the whole process of drilling in this article, different parameters have different recognition degrees of stratigraphic structure. For example, the value of axial pressure increases obviously at the concrete interlayer and dike interlayer, which indicates that the axial pressure is more sensitive to the rock with higher hardness, but the variation law is not obvious for the strata with grade IV to III/II. The flushing fluid pressure is more sensitive to the changes in the stratum structure from grade VI to grades IV/III. For the strata with grades III/II or higher strength grade, the regularity of its numerical value is not obvious. Rotation speed has a better recognition effect on formations with lower or higher strength grades and poor recognition effect on rock masses with grade V to III/II. There are many reasons for these uncertainties and differences, and it is difficult to eliminate them by simple technical means. Therefore, it is necessary to consider the combined effect of multiple factors when using drilling parameters to identify the formation structure.

From the analysis of this article, the accuracy of the recognition of the formation structure and strength based on the drilling specific energy is higher than that of a single drilling parameter. This is because more drilling parameters are considered in the calculation formula of drilling specific energy. When a certain parameter has an error within a certain range, other parameters can be appropriately corrected. On the other hand, because the drilling rig parameters are easily affected by the operating habits of different drilling rig operators, from the energy point of view, the errors caused by the different operating methods of the drilling rig operators can be reduced. At the same time, it is worth noting that the specific energy value of drilling in the method based on energy analysis is obtained by taking the average value according to the calculation results of different strength formations. Although the drilling specific energy has the obvious numerical distinction in different weathered formations, its variation range is large. The upper and lower bounds of the drilling specific energy of adjacent strength grades of rock mass will 
TABLE 14: Rock classification and compressive strength statistics based on drilling specific energy.

\begin{tabular}{|c|c|c|c|c|c|c|}
\hline \multirow{2}{*}{ Rock classification } & \multirow{2}{*}{ Compressive strength $(\mathrm{MPa})$} & \multicolumn{5}{|c|}{ Drilling specific energy $\left(\mathrm{kN} \cdot \mathrm{m} \cdot \mathrm{cm}^{-3}\right)$} \\
\hline & & Drill hole 1 & Drill hole 2 & Drill hole 3 & Drill hole 4 & Drill hole 5 \\
\hline VI (fill) & 0.06 & - & 0.0214 & - & - & - \\
\hline $\mathrm{V}$ & 0.7 & 0.0365 & 0.0297 & 0.0208 & 0.0245 & 0.0285 \\
\hline $\mathrm{V} / \mathrm{IV}$ & 12.92 & 0.1056 & 0.0942 & 0.1215 & 0.1105 & 0.0956 \\
\hline IV (concrete) & 28.44 & - & $0.2798 /$ & - & - & - \\
\hline IV & 35.85 & 0.2212 & 0.2564 & 0.2487 & 0.2858 & 0.2452 \\
\hline IV/III & 52.76 & 0.2469 & 0.3124 & 0.3345 & 0.2726 & 0.2744 \\
\hline III & 67.62 & 0.3849 & - & 0.3226 & 0.3419 & 0.4009 \\
\hline III/II & 86.81 & 0.6512 & 0.6842 & 0.6429 & 0.6145 & 0.7032 \\
\hline II & 100.36 & 1.2365 & 1.1256 & - & 1.1736 & 1.3456 \\
\hline II/I (vein) & 115.78 & 1.3769 & 1.4029 & - & - & 1.4896 \\
\hline
\end{tabular}

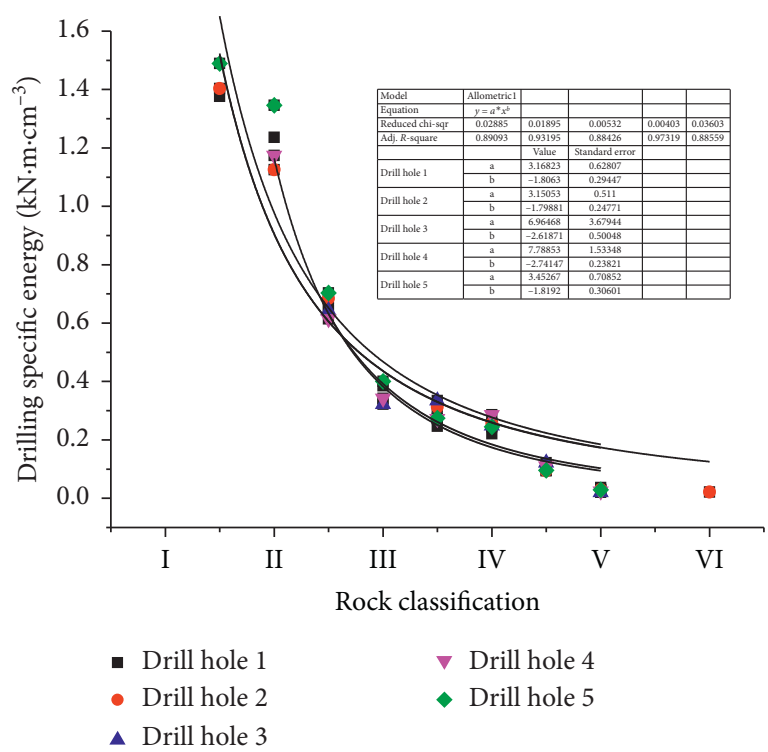

(a)

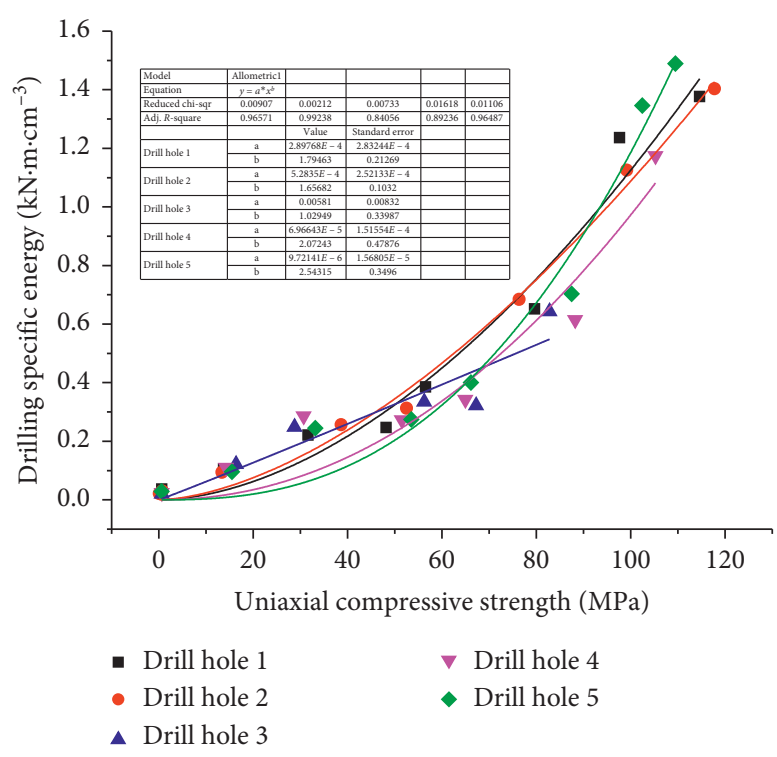

(b)

FIGURE 15: The relationship between rock classification, compressive strength, and drilling specific energy.

TABLE 15: Statistics of rock structure types based on drilling specific energy.

\begin{tabular}{|c|c|c|c|c|}
\hline Rock classification & VI-V/IV & IV-III & III/II & II-II/I \\
\hline Rock & Soil and soft rock & Fragmented hard rock & Medium hard rock & Hard rock \\
\hline$f(-3)-3)$ & 0.0626 & 0.2952 & & 1.2915 \\
\hline Range of drilling specific energy $\left(\mathrm{kN} \cdot \mathrm{m} \cdot \mathrm{cm}^{-3}\right)$ & $0.0116-0.5785$ & $0.0685-0.7496$ & $0.2598-1.1268$ & $0.7635-2.6951$ \\
\hline
\end{tabular}

TABLE 16: Rock strength prediction model based on drilling specific energy.

\begin{tabular}{lccc}
\hline Parameter & $\begin{array}{c}\text { Rock classification } \\
\text { Formula }\end{array}$ & $R^{2}$ & $\begin{array}{c}\text { Compressive strength/MPa } \\
\text { Formula }\end{array}$ \\
\hline Drilling specific energy & $\mathrm{RMC}=3.4323 E_{d}^{-1.8859}$ & 0.93 & $\sigma_{c}=94.97757 E_{d}^{0.60556}$ \\
\hline
\end{tabular}

have overlapping areas. However, such phenomena are rarely seen in the results of tests in the laboratory. This is because natural rock masses, especially those with varying degrees of weathering, contain heterogeneous structures such as various natural cracks, joints, and weak interlayers, which will cause the specific energy of the drilling rig to jump. However, for the rock mass of the mechanical test, there are fewer structural planes and the integrity of the rock mass is better, so the range of the numerical statistical results is relatively small. Therefore, in actual engineering, 
when recognizing formation results by drilling specific energy methods, a more reasonable data processing method should be selected to make the calculation results more recognizable.

\section{Conclusions}

(1) A rotary drilling rig was used to conduct field drilling experiments on the weathered granite site, and the drilling process was monitored in real time through the geological identification while drilling system (GIWD), and five main drilling parameters of the drilling process were obtained. By setting the threshold value of each drilling subprocess, combined with the computer coding identification method, compared with the traditional drilling monitoring system, the identification system can more effectively remove invalid data and extract the true drilling parameters.

(2) Through the analysis of axial pressure, rotation speed, flushing fluid pressure, drilling rate, and torque during the drilling process, the geological structure composition of the typical granite formation was predicted. By comparing with the field survey results, the formation structure prediction based on drilling parameters is feasible, and there is a certain response relationship between different parameters, and the rock strength prediction formula based on drilling parameters is given. According to the accuracy of the prediction results from high to low, the ranking is in order of drilling rate, axial pressure, torque, rotation speed, and flushing fluid pressure.

(3) Through the calculation formula of drilling specific energy established based on the principle of energy conservation, the energy consumption of formations with different strengths during the drilling process is calculated, and the prediction formula of rock and soil strength is based on the drilling specific energy method given. The analysis results show that, compared with the single drilling parameter identification method of the formation structure, the prediction accuracy of the formation structure and strength prediction method based on the drilling specific energy is higher, which can meet the needs of practical engineering applications. From the analysis of the text, we can see that, for the formation of the same strength level, the drilling specific energy has a larger range of variation. This will lead to adjacent formations with different strengths, and there will be overlapping areas of drilling specific energy. Therefore, how to narrow the range of drilling specific energy in the same formation and further improve the prediction accuracy will be a key research topic in the future.

\section{Data Availability}

The data included in this study are available from the corresponding author upon request.

\section{Conflicts of Interest}

The authors declare that they have no conflicts of interest.

\section{Acknowledgments}

The authors would like to thank the National Natural Science Foundation of China (No. 51574015), the National key R\&D Program of China (2018YFC0808701), the China Postdoctoral Science Foundation (2020M673525), and China Railway 20th Bureau Group Co., Ltd. (YF2000SD01A).

\section{References}

[1] International Organization for Standardization (ISO), Geotechnical Investigation and Testing Identification and Classification of Rock Part 1: Identification and Description, International Organization for Standardization (ISO), Geneva, Switzerland, 2003.

[2] D. Standards, "Geotechnical investigation and testing: laboratory testing of soil part 12: determination of Atterberg limits," ZAMM-Journal of Applied Mathematics and Mechanics/Zeitschrift für Angewandte Mathematik und Mechanik, vol. 89, no. 1, p. 43, 2009.

[3] V. Eitner, R. Katzenbach, and F. Stoelben, "International and European standards on geotechnical investigation and testing for site characterization," in Geotechnical and Geophysical Site Characterizationvol. 1, 2004.

[4] R. Ulusay, The ISRM Suggested Methods for Rock Characterization, Testing and Monitoring: 2007-2014, Vol. 15, Springer International Publishing, New York, NY, USA, 2014.

[5] R. Carroll and M. Long, "Sample disturbance effects in silt," Journal of Geotechnical \& Geoenvironmental Engineering, vol. 143, no. 9, Article ID 04017061, 2017.

[6] Z. Li, S. Y. Li, K. Wu, G. J. Cai, L. Y. Tong, and L. W. Liu, "Determination of the disturbance depth due to excavations using multifunctional CPTU tests," Chinese Journal of Geotechnical Engineering, vol. 10, pp. 1-7, 2020.

[7] G. M. Peng and Z. Liu, "An overview of joint electromagneticseismic inversion and its future development," Oil Geophysical Prospecting, vol. 055, no. 2, pp. 465-474, 2020.

[8] D. Colombo, G. McNeice, E. S. Curiel, and A. Fox, "Full tensor CSEM and MT for subsalt structural imaging in the Red Sea: implications for seismic and electromagnetic integration," The Leading Edge, vol. 32, no. 4, pp. 436-449, 2013.

[9] E. M. T. Takougang, B. Harris, A. Kepic, and C. V. A. Le, "Cooperative joint inversion of 3D seismic and magnetotelluric data: with application in a mineral province," Geophysics, vol. 80, no. 4, pp. 175-187, 2015.

[10] L. Zhenchun, "Research status and development trends for seismic migration technology," Oil Geophysical Prospecting, vol. 49, no. 1, pp. 1-21, 2014.

[11] Q. Wang, Q. Qian, S. Gao et al., "Relationship between rock drilling parameters and rock uniaxial compressive strength based on energy analysis," Journal of China Coal Society, vol. 43, no. 5, pp. 1289-1295, 2018. 
[12] J. Chen and Z. Q. Yue, "Weak zone characterization using full drilling analysis of rotary-percussive instrumented drilling," International Journal of Rock Mechanics and Mining Sciences, vol. 89, pp. 227-234, 2016.

[13] T. Zhuoying and X. Kaiwen, "Key techniques for intelligent drilling in geotechnical engineering," Metal Mine, vol. 4, no. 1, pp. 1-4, 2011.

[14] J. Peck and J. Vynne, "Current status and future trends of monitoring technology for drills," in Proceedings of International Mining Geology Conference, pp. 311-325, Kalgoorlie, Australia, July 1993.

[15] M. L. Stefan, Geological Well Logs: Their Use in Reservoir Modeling, Springer, London, UK, 2000.

[16] P. Pfister, "Recording drilling parameters in ground engineering," Ground Engineering, vol. 18, no. 3, pp. 16-21, 1985.

[17] J. P. Hamelin, J. Levallois, and P. Pfister, "Enregistrement des parametres de forage: nouveaux développements," Bulletin of the International Association of Engineering Geology Bulletin De Lassociation Internationale De Géologie De Lingénieur, vol. 26, pp. 83-88, 1982.

[18] F. Fortunati and G. Pellegrino, "Cooperative joint inversion of 3D seismic and magnetotelluric data: with application in a mineral province," Geophysics, vol. 80, no. 4, pp. 175-187, 2015.

[19] C. E. Tsoutrelis, "Determination of the compressive strength of rock in situ or in test blocks using a diamond drill," International Journal of Rock Mechanics and Mining Sciences \& Geomechanics Abstracts, vol. 6, no. 3, pp. 311-321, 1969.

[20] D. F. Howarth, W. R. Adamson, and J. R. Berndt, "Correlation of model tunnel boring and drilling machine performances with rock properties," International Journal of Rock Mechanics and Mining Sciences \& Geomechanics Abstracts, vol. 23, no. 2, pp. 171-175, 1986.

[21] J. Peck, M. J. Scoble, and M. Carter, "Interpretation of drilling parameters for ground characterization in exploration and development of quarries," Transactions of the Institution of Mining and Metallurgy, vol. 96, no. 8, pp. 141-148, 1987.

[22] H. Schunnesson, "RQD predictions based on drill performance parameters," Tunnelling and Underground Space Technology, vol. 11, no. 3, pp. 345-351, 1996.

[23] M. W. Gui, K. Soga, M. D. Bolton, and J. P. Hamelin, "Instrumented borehole drilling for subsurface investigation," Journal of Geotechnical and Geoenvironmental Engineering, vol. 128, no. 4, pp. 283-291, 2002.

[24] Z. Q. Yue, C. Lee, K. Law, L. Tham, and J. Sugawara, "Use of HKU drilling process monitor in slope stabilization," Chinese Journal of Rock Mechanics and Engineering, vol. 21, no. 11, pp. 1685-1690, 2002.

[25] Z. Q. Yue, C. F. Lee, K. T. Law, and L. G. Tham, “Automatic monitoring of rotary-percussive drilling for ground characterization-illustrated by a case example in Hong Kong," International Journal of Rock Mechanics and Mining Sciences, vol. 41, no. 4, pp. 573-612, 2004.

[26] Z. Q. Yue, J. Chen, and W. Gao, “Automatic drilling process monitoring (DPM) for in-situ characterization of weak rock mass strength with depth," in Proceedings of the Paper presented at the 1st Canada-U.S. Rock Mechanics Symposium, Vancouver, Canada, May 2007.

[27] Z. Q. Yue, "Drilling process monitoring for refining and upgrading rock mass quality classification methods," Chinese Journal of Rock Mechanics and Engineering, vol. 33, no. 10, pp. 1977-1996, 2014.

[28] Z. Q. Yue, W. Gao, J. Chen, and C. F. Lee, "Drilling process monitoring for a wealth of extra factual data from drillhole site investigation," in Proceedings of the 10th International Congress of the International Association of Engineering Geology (IAEG2006 Engineering Geology for Tomorrow's Cities), Nottingham, UK, September 2006.

[29] S. S. Peng, T. Sasaoka, D. X. Tang, L. Yi, and G. Wilson, "Mine roof geology information system," Coal Age, vol. 110, 2005.

[30] H. Zhou, S. T. Monteiro, P. Hatherly, F. Ramos, and F. Oppolzer, "Spectral feature selection for automated rock recognition using gaussian process classification," 2009.

[31] A. Kadkhodaie-Ilkhchi, S. T. Monteiro, F. Ramos, and P. Hatherly, "Rock recognition from MWD data: a comparative study of boosting, neural networks, and fuzzy logic," IEEE Geoscience and Remote Sensing Letters, vol. 7, no. 4, pp. 680-684, 2010.

[32] C. W. Zang, "Review on relationship between drilling rate and rock mechanical parameters in a tunnel," Chinese Journal of Underground Space and Engineering, 2008.

[33] H. Tian, L. S. Cai, Y. G. Xue, D. H. Qiu, M. X. Su, and K. Wang, "Identification of interface of tuff stratum and classfication of surrounding rock of tunnel using drilling energy theory," Rock and Soil Mechanics, vol. 33, no. 8, pp. 2457-2464, 2012.

[34] A. Patel, "Characterization of cavities in rocks using drilling parameters," International Journal of Rock Mechanics and Mining Sciences, vol. 63, pp. 122-130, 2013.

[35] S. W. Liu, Y. L. Feng, and D. L. Liu, "Numerical experiments of dynamic response characteristics of rock drilling on stratified roof in coal roadway," Chinese Journal of Rock Mechanics and Engineering, vol. 33, pp. 3170-3176, 2014.

[36] R. Leung and S. Scheding, "Automated coal seam detection using a modulated specific energy measure in a monitorwhile-drilling context," International Journal of Rock Mechanics and Mining Sciences, vol. 75, pp. 196-209, 2015.

[37] O. Su, U. Sakız, and N. A. Akçın, "Effect of elastic and strength properties of rocks during blasthole drilling," Rock Mechanics and Rock Engineering, vol. 1, pp. 217-222, 2016.

[38] A. Asadi, A. Abbasi, and A. Bagheri, "Application of artificial neural networks in estimation of drilling rate index using data of rock brittleness and mechanical properties," in Proceedings of the Nordic Rock Mechanics Symposium, Helsinki, Finland, October 2017.

[39] Y. W. Fang, Z. J. Wu, Q. Sheng, H. Tang, and D. C. Liang, "Intelligent recognition of tunnel stratum based on advanced drilling testing," Rock and Soil Mechanics, vol. 41, no. 7, pp. 1-10, 2020 .

[40] H. K. Gao, Q. Wang, B. Jiang, P. Zhang, Z. Jiang, and Y. Wang, "Relationship between rock uniaxial compressive strength and digital core drilling parameters and its forecast method," International Journal of Coal Science \& Technology, 2021.

[41] R. Teale, "The concept of specific energy in rock drilling," International Journal of Rock Mechanics \& Mining Ences and Geomechanics Abstracts, vol. 2, no. 2, pp. 57-73, 1965.

[42] H. Karasawa, T. Ohno, M. Kosugi, and J. C. Rowley, "Methods to estimate the rock strength and tooth wear while drilling with roller-bits-part 2: insert bits," Journal of Energy Resources Technology, vol. 124, no. 3, p. 133, 2002.

[43] Z. Y. Tan, M. Cai, Z. Yue, L. Tham, and C. Lee, "Interface identification of intricate weathered granite ground investigation in Hong Kong using drilling parameters," Chinese Journal of Rock Mechanics and Engineering, vol. 25, pp. 2939-2945, 2006.

[44] Z. Y. Tan, M. Cai, Z. Yue, L. Tham, and C. Lee, "Interface identification in weathered granite strata based on a 
instrumented drilling system," Journal of University of Science \& Technology Beijing, vol. 29, no. 7, pp. 665-669, 2007.

[45] Z. Y. Tan, Z. Yue, L. Tham, and C. Lee, "Relationship between diamond penetrating energy and weathered degree in granite formation," Journal of University of Science and Technology Beijing, vol. 30, no. 4, pp. 339-343, 2008.

[46] Z. Y. Tan, L. I. Wen, P. J. Yue et al., "Techniques and approaches for identification of geo-formation structure based on diamond drilling parameters," Chinese Journal of Geotechnical Engineering, 2015.

[47] S. C. Li, Y. G. Xue, H. Tian, Z. Q. Li, and Z. C. Wang, "Identifying the geological interface of the stratum of tunnel granite and classifying rock mass according to drilling energy theory," Arabian Journal of Geosciences, vol. 9, no. 1, pp. 1-11, 2016.

[48] J. S. Chen, H. S. Deng, M. Z. Gao, Y. H. Cheng, and C. L. Wang, "Study on identification along with drilling of roof strata of excavation roadway," Journal of Mining and Safety Engineering, vol. 33, no. 2, pp. 272-276, 2016.

[49] S. Li, R. Huo, F. Yoshiaki, D. Ren, and Z. Song, "Effect of acidtemperature-pressure on the damage characteristics of sandstone," International Journal of Rock Mechanics and Mining Sciences, vol. 122, Article ID 104079, 2019.

[50] S. G. Li, Y. M. Wu, R. K. Huo, Z. P. Song, F. Yoshiaki, and Y. J. Shen, "Mechanical properties of acid-corroded sandstone under uniaxial compression," Rock Mechanics and Rock Engineering, vol. 54, no. 1, 2020.

[51] K. Wu, Z. Shao, S. Qin, W. Wei, and Z. Chu, "A critical review on the performance of yielding supports in squeezing tunnels," Tunnelling and Underground Space Technology, 2021.

[52] K. Wu, Z. Shao, and S. Qin, "An analytical design method for ductile support structures in squeezing tunnels," Archives of Civil and Mechanical Engineering, vol. 20, 2020.

[53] K. Wu and Z. Shao, "Visco-elastic analysis on the effect of flexible layer on mechanical behavior of tunnels," International Journal of Applied Mechanics, vol. 11, no. 3, Article ID 1950027, 2019.

[54] Z. Y. Tan, Q. Yue, and M. Cai, “Analysis of energy for rotary drilling in weathered granite formation," Chinese Journal of Rock Mechanics and Engineering, vol. 26, no. 3, pp. 478-483, 2007. 